\title{
Study on the interaction between active components from traditional Chinese medicine and plasma proteins
}

\author{
Qishu Jiao, Rufeng Wang, Yanyan Jiang and Bin Liu*
}

\begin{abstract}
Traditional Chinese medicine (TCM), as a unique form of natural medicine, has been used in Chinese traditional therapeutic systems over two thousand years. Active components in Chinese herbal medicine are the material basis for the prevention and treatment of diseases. Research on drug-protein binding is one of the important contents in the study of early stage clinical pharmacokinetics of drugs. Plasma protein binding study has far-reaching influence on the pharmacokinetics and pharmacodynamics of drugs and helps to understand the basic rule of drug effects. It is important to study the binding characteristics of the active components in Chinese herbal medicine with plasma proteins for the medical science and modernization of TCM. This review summarizes the common analytical methods which are used to study the active herbal components-protein binding and gives the examples to illustrate their application. Rules and influence factors of the binding between different types of active herbal components and plasma proteins are summarized in the end. Finally, a suggestion on choosing the suitable technique for different types of active herbal components is provided, and the prospect of the drug-protein binding used in the area of TCM research is also discussed.
\end{abstract}

Keywords: Active components, Traditional Chinese medicine, Plasma protein binding, Research methods

\section{Introduction}

Traditional Chinese medicine (TCM) is the summary of practical experience of Chinese people for thousands of years in the fight against disease. It is the treasure of Chinese culture and constitutes multi-billion-dollar markets-more than 1500 kinds of herbal medicines are sold as dietary supplements or the raw material of medicines [1]. Its active components are the substantial basis for the treatment of various diseases and the related study is also one of the most important parts of the modernization of Chinese herbal medicine.

Generally speaking, the concentration of the free active (or toxic) components is directly related to the biological effect (or poisoning), and the concentration of the free drugs in plasma is directly related to the concentration in the tissue. When drugs are absorbed into the

*Correspondence: liubinyn67@163.com

School of Chinese Pharmacy, Beijing University of Chinese Medicine, Beijing 102488, China blood, drug-plasma protein binding (PPB) is a common and reversible dynamic process [2]. PPB is one of the important parameters of drug efficacy and safety, and the determination of bound fraction is a necessary step in drug discovery and clinical trials [3]. It determines the pharmacokinetic and pharmacodynamic characteristics of drugs and influences drug absorption, distribution, metabolism, excretion and toxicity (ADMET) $[4,5]$. It is generally considered that only free drug can transfer through biological membranes, combine with the appropriate site of action and drive the therapeutic outcome [6]. And then it displays the pharmacological and/ or toxicological effects [7]. Small molecular substances can be protected from some elimination pathways, such as enzymatic reactions in the liver or blood and glomerular filtration of the kidneys, by forming non-covalent complexes with plasma proteins [8]. As a drug reservoir, the bound drug fraction can maintain an effective concentration and prolong the duration of the drug action. For the drugs with high affinity for plasma proteins, they 
generally need a higher dose to reach therapeutic level, have a long half-life and probably increase toxicity. Conversely, the drugs with low plasma protein binding affinities are limited in their ability to perfuse tissues and reach the site of action [9].

Although many Chinese herbal medicines have been proved to be effective by modern clinical trials and pharmacological studies, their active components and the remedial mechanism are still unclear [10]. The pharmacological activities of Chinese herbal medicines are considered to be the combination of multi-components effects, including the interactions of active components with proteins. It is well known that a kind of herbal medicine usually contains hundreds of different components [11]. There is no doubt that this is a complex and heavy work to elucidate the mechanism of action of these components. Therefore, it is extremely valuable to investigate the binding of one or a few active components from Chinese herbal medicine with plasma proteins.

\section{Plasma proteins involved in drug binding}

Major drug-binding proteins in plasma are human serum albumin (HSA), $\alpha_{1}$-acid glycoprotein (AAG) and lipoproteins [12]. They have many important physiological functions, for example, mediating osmotic pressure and nutrient delivery, participating in the clot formation and immune response [13]. It is generally accepted that acidic drugs display greater affinity for HSA, while AAG is primarily responsible for the binding of neutral and acidic drugs [14]. HSA, as the most abundant protein in plasma proteins, is in a position to bind endogenous ligands (e.g., fatty acids, amino acids, hormones, bile acids, metals and toxic metabolites) as well as drugs [15-17]. AAG is the second most abundant one, and its endogenous ligands include heparin, serotonin, histamine, steroid hormones and so on [18]. Research reporting on drugs binding to lipoprotein is still sparse.

As the most abundant plasma protein with amazing properties and functions, HSA is the most widely explored protein which is always used as the ligand-biological macromolecules interaction model [19]. Through the first crystallographic analyses of HSA, it is revealed that the protein, as a kind of nonglycosylated molecules, consists of 585 amino acids and 35 cysteine residues, forming 17 disulfides and one free sulfhydryl group at Cys34. The classical researches revealed that the atomic structure of HSA consists of three homologous $\alpha$-helical domains (I-III) each including two subdomains (A and B) [20]. The protein has two high affinity drug binding sites, named as Sudlow's sites in subdomain IIA and IIIA [8]. Drug site 1 (subdomain IIA) is composed of three extended sub-chambers and a central zone. The inside of the pocket is mainly non-polar molecules. Two clusters of polar residues located in the bottom (Tyr 150, His 242, Arg 257) and the entrance (Lys 195, Lys 199, Arg 218, Arg 222) are also identified. Drug site 1 is occupied by phenylbutazone and warfarin. Drug site 2 (subdomain IIIA) is smaller than site 1, but it can accommodate large molecules, such as ibuprofen and thyroxine. In addition, there is another binding site named site 3, to which the digitoxin binds. Because of the structural homology with HSA, bovine serum albumin (BSA) is also a common interaction model used for investigating PPB [21].

\section{Methods to investigate the interaction between active herbal components and plasma proteins}

In recent years, with the development of Chinese herbal medicine, researchers have been paying more and more attention to the pharmacological activity of components in herbal medicine, and numerous experimental techniques have been used in the characterization of PPB. The work has become increasingly diverse and detailed by the application of spectroscopy, chromatography, thermodynamics, electrochemistry and other techniques. The principle and the detection methods of current analysis tool have been introduced in several theses $[8,19$, 22]. In this article, a brief introduction of common methods is given, and the applications of techniques used in the investigation of the interaction between active herbal components with plasma proteins are described in detail.

\section{Membrane technology \\ Equilibrium dialysis (ED)}

ED, combined with highly-sensitive assay, such as high performance liquid chromatography (HPLC) and mass spectrometry (MS), is regarded as the gold standard to determine protein binding rate. The working principle of ED is that the small drug molecules could be separated from protein solution by semipermeable membrane. The small drug molecules could pass through the semipermeable membrane until the dialysis reaches equilibrium, while the drug-protein complexes are retained in the dialysis bag. The binding rates of drug molecules with plasma proteins can be calculated by measuring the concentrations of small molecules in the solution on both sides. ED is an easy, economical, practical method and can eliminate the possible effect of non-specific binding $[23,24]$. In recent years, ED has been widely used in the multi-component drug research in Chinese herbal medicine. Liu et al. investigated the effects of sinomenine on the therapeutic action of paeoniflorin in the treats-rats by an equilibrium dialysis assay in vitro $[25,26]$. The results showed that the protein binding ability is not influenced when they are administrated simultaneously. Wang et al. used a kind of dialysis sampling on-line coupled with 
HPLC (DS-HPLC) to monitor the interactions of multicomponents in danshen (Salvia miltiorrhiza) injection with BSA [27]. The five components (danshensu, protocatechuic acid, protocatechuic aldehyde, caffeic acid and ferulic acid) in danshen injection had suitable binding degrees with BSA. Talbi et al. found that wogonin had a very high protein binding degree (over 90\%) with rat plasma [28].

But ED also has disadvantages in some ways, including a long time for balancing, the strict control of the $\mathrm{pH}$ of plasma and buffer solution, dilution effect and Gibbs-Donnan effects, etc. [19, 29-31]. In recent years, the equilibrium dialysis devices based on the 48-well and 96-well plates have been used in the plasma protein binding studies [32]. The unique design of the device increases the surface area-to-volume ratio and offers the possibility of reducing equilibration times and higher assay throughput. Compared with traditional equilibrium dialysis, this device also has many advantages including easy-to-clean, reusability, the reduction of the drug nonspecific absorption and capability of being automated. As the early screening tools for drug research, rapid equilibrium dialysis (RED) device and parallel artificial membrane permeability assay (PAMPA) are two major in vitro models based on Teflon base plate.

The RED device comprises replaceable tube inserts and a 48-well Teflon base plate. Each insert is divided into a buffer compartment (white) and a plasma compartment (red) by a semipermeable membrane at molecular weight cut-off $(\mathrm{MWCO})=8000$. Each plate could be sealed with sealing tape and self-adhesive lid. The volume of the insert should be checked to guarantee the little to no volume change occurred [33-35]. Kim et al. developed a RED device combined with LC-MS/MS method to quantify the acacetin in human plasma [36]. The results showed a concentration-independent and extensive protein binding of acacetin in human plasma. The general PAMPA plate system consists of an acceptor compartment (96-well filter plate) and a donor compartment (96-well receiver plate) [37]. Each well of the 96-well microfiltration membrane is filled with $10 \mu \mathrm{L}$ of the artificial membrane solution which is made of film-forming material dissolved in organic solvent. The 96-well filter plate will be placed on the receiver plate to allow the artificial membrane to touch the donor fluid. And thus the system forms a sandwich structure: the bottom is the donor liquid of the sample, and the drug molecules diffuse from the donor tube into the upper receptor tube through the artificial membrane. When the diffusion is completed, the receptor fluid and the donor fluid can be used to make quantitative analysis [38, 39]. Singh et al. investigated the blood uptake characteristics, protein binding, pharmacokinetics and metabolism of formononetin by this system. Formononetin had high protein binding rate, and the rapid absorption of which might due to the high permeability and lipophilicity [40].

\section{Ultrafiltration}

Ultrafiltration is a popular alternative of ED and a better choice for the clinical pharmacokinetic and pharmacodynamic studies of new drugs [41]. Similar to ED, it utilizes semipermeable membrane to separate the device into two chambers. Driven by the pressure difference or centrifugation (approximately $2000 \times g$ ), the drug molecules diffuse through the semipermeable membrane. Because this method achieves the rapid separation of small molecules in plasma, the work efficiency is greatly increased [42]. Ultrafiltration is more suitable for highly lipophilic compounds, and it, in combination with HPLC, GC-MS, LC-IT-TOF-MS, RRLC-ESI-MS-MS and other high sensitivity detection methods, has been applied to determine the plasma protein binding rate of active herbal components [43-50].

In ultrafiltration, the concentration polarization, which is caused by the diffuse direction of the small molecules, is perpendicular to the ultrafiltration membrane. It will compromise the protein-binding equilibrium and affect the determination of free drug concentration. Li et al. developed a novel and practical method based on hollow fiber centrifugal ultrafiltration (HFCF-UF) combined with HPLC to determine the plasma protein binding of three coumarins in human plasma [51]. The device was made of a glass tube, in which a U-shaped hollow fiber was placed. Therefore, the direction of molecular diffusion was completely parallel to the membrane. The binding rates of bergenin, daphnetin, and scopoletin determined by this method were 52.7-53.5, 56.7-58.0 and $59.0-60.1 \%$ respectively, which were consistent with the results of the equilibrium dialysis method. Compared with the classical method, HFCF-UF has higher precision and accuracy and simpler sample preparation procedure.

\section{Microdialysis}

Microdialysis was originally used to determine the free adenosine levels in the brain of rats [52]. In recent years, it has become an important technique for direct determination of the free drug concentration in the body's plasma, tissue and other physiological fluids. The key of this technique is the probe with a semipermeable membrane which has a molecular mass cut-off ranging from 5000 to $50,000 \mathrm{Da}$ [53]. The biggest advantage of microdialysis is the real-time sampling and on-line analysis in a condition that hardly interfered with the normal life activity of animals [54]. With this method, we can continuously measure the concentration of unbound drug over time in vivo [55]. Another advantage of microdialysis is 
the convenience for automation that hyphenated with many sensitive analytical techniques like HPLC, capillary electrophoresis (CE), nuclear magnetic resonance (NMR), etc. [56].

Microdialysis has many features in the field of traditional Chinese medicine. The most prominent feature is the ability to simultaneously investigate the interaction of multi-components in Chinese herbal medicine or compound prescription with plasma proteins, and thus finding the potential active components [57]. Qian et al. found that chlorogenic acid, luteolin-3-O-glucoside and 4,5-di-O-caffeoyl quinic acid might compete for the same binding sites and caffeic acid and rutin had synergistic effects in Flos Lonicerae Japonicae [58]. Wen et al. found that four compounds (chlorogenic acid, calycosin-7-O- $\beta$ $D$-glucoside, ferulic acid and calycosin) in Danggui Buxue Decoction had suitable binding degrees with human plasma proteins [10]. These compounds had been proven to be the active components in the prescription. Guo et al. found that compound I and compound $M$ identified in Rhizoma Chuanxiong had the similar binding degrees to HSA as two known active compounds, ferulic acid and 3-butylphthalide [59]. They thought compound I and compound $\mathrm{M}$ might be the potential active compounds. The online coupling of microdialysis with sensitive and selective analytical systems has great value and potential in screening the effective components from Chinese herbal medicine.

\section{Centrifugation}

Other than the membrane techniques like ED and UF, ultracentrifugation (UC) techniques separate the free drug molecule from the drug-protein complex by high gravitational force $(625,500 \mathrm{~g})$. Small molecules and proteins have different density or sedimentation rate in centrifugal force field. After centrifugation, the drug molecules combined with high density plasma macromolecules will rapidly subside to the bottom, while the free fraction can be quantitated in the supernatant of the centrifuge tube $[8,60]$. UC has several advantages such as the lack of Gibbs-Donnan effects and nonspecific adsorption, adoptability for high molecular weight and lipophilic compounds [61]. But the limit factors, like the expensive equipment and the low throughput caused by the relatively smaller number of samples that can be processed at one time, restrict the application of $\mathrm{UC}$ techniques. Li et al. removed the plasma proteins by ultracentrifugation and measured the concentration of syringopicroside in serum by HPLC after injection of low, medium and high doses [62]. The results showed that syringopicroside was a medium plasma protein binding drug and the binding rate was not dependent on the doses.

\section{Extraction methods}

\section{Solid phase microextraction (SPME)}

SPME is a simple and effortless technique to determine free drug concentration [63]. It was developed as a convenient method for volatile organic compounds in the early 1990s. Because of its simplicity, SPME has been used to monitor the metabolites, ligand-protein binding, toxicity and permeability of drugs, and metabonomics of volatile or semivolatile compounds. Basic theory of this technique is that the solid support, which is hydrophobic and dispersed with extracting phases, is exposed to the test sample for a definite period of time [64]. Then, the enriched drug molecules in the extraction phase are rapidly and completely separated into the analytical instruments by high temperature or solvent elution methods. SPME fiber is an optical glass fiber which is evenly coated with a polymer coating [65]. Because of the non-depleting extraction mode, SPME is a particular suitable technique for drug-protein binding studies [66]. The development of biocompatible coating makes SPME can investigate complex biological samples for any binding equilibriums $[64,67]$. The relative high accuracy and sensitivity, no need to use organic solvents and possibility to automate are the main advantages of SPME. But the fouling formed of protein-fiber binding may lead to erroneous estimate of the concentration in the fiber coating $[63,65]$.

SPME has been used in investigating the interaction between active components in TCMs and plasma proteins [68-70]. Volatile oil widely exists in traditional Chinese medicine derived from plants. It is well known that there are 136 genera of 56 families in China containing volatile oil. In addition to volatile oil, there are many aromatic substances of Chinese medicine, such as musk, bezoar and borneol. These components are complex, volatile and insoluble in water. Therefore, conventional methods are difficult to determine the binding degrees of these components with plasma proteins. Headspace-SPME, in which the extraction fiber is placed in the upper space of the samples, is more suitable for the determination of these components. The extraction head of headspace-SPME does not touch the sample, and thus avoids the matrix effect. Hu et al. developed a headspace negligible-depletion extraction mode (nd-SPME) coupled to GC method to investigate the noncovalent interaction of borneol with HSA [71]. The method was simple, sensitive, rapid and could overcome the drawback of losing volatile components in the binding or transfer process.

\section{Hollow fiber liquid-liquid phase microextraction (HF-LLPME)}

HF-LLPME is an inexpensive sample preparation method to investigate the drug-protein binding under physiological conditions without disturbing the equilibrium 
between drugs and proteins [72]. In microextration system, the polypropylene hollow-fiber membrane is filled with $15-25 \mu \mathrm{L}$ of extraction solvent and placed into the mixture of drug and protein. When small molecule drugs establish distribution equilibrium between bulk aqueous phase and organic phase, the unbound concentration of drugs can be determined by analytical instrument [73, 74]. This method allows simultaneous determination of multi-components. Compared with the traditional liquid-liquid extraction (LLE), HF-LLPME allows the sample under vigorous stirring conditions and requires less organic solvents. Therefore, the method reduces the analysis time of drugs transferred across the membrane. HFLLPME has potential to determine drug-protein binding of active components from TCMs in the complex sample matrices. Hu et al. investigated the interaction of four furocoumarin and two alkaloid compounds with BSA by HF-LLPME combined with HPLC [75, 76]. The results demonstrated that HF-LLPME is a simple, rapid and effective method for characterizing drug-protein binding parameters without separation.

\section{Chromatographic methods High performance affinity chromatography (HPAC)}

HPAC is a kind of adsorption chromatography which uses a biologically related agent as stationary phase [77]. As one of the most effective methods that separate and purify the biological macromolecules, HPAC is based on the specific reversible interaction between the target protein and the immobilized ligand. HPAC immobilizes the proteins onto a support and injects the interacting solute into the column. The drugs with high affinities will be eluted later than low-affinity drugs because of the strong interaction [78]. The method has been coupled with HPLC to determine the binding of drugs and various proteins such as HSA, AGP and lipoproteins in plasma [79]. Many reports have demonstrated that the allosteric interactions and displacement effects seen on HSA columns are similar to those observed for soluble HSA [80, 81]. Compared to the traditional methods, HPAC has many advantages such as automation, high precision, speed, specificity and the ability to work with small amounts of a target solute $[82,83]$. But some problems still need to be solved, such as the short service life of the column and the high standards of the preparation of fillers.

For complex research objects, such as Chinese herbal medicines, HPAC could eliminate the interference of a large number of inactive impurities due to the specificity and selectivity of the stationary phase in combination with the active component. Cai et al. detected the binding rates of puerarin and goitrin with HSA by a HSA column [84]. The results were consistent with those obtained by ultrafiltration method and demonstrated that HPAC method was a reliable technique. HPAC is often applied to investigate the competition displacement in different active herbal components with plasma proteins. Lei et al. investigated the competition interaction of ferulic acid and paeonol with HSA by HPAC [85]. The results demonstrated that ferulic acid and paeonol competed for binding to the indole site (site 2) and the main force was deduced to be hydrogen bonding according to the thermodynamic parameters.

\section{Capillary electrophoresis (CE)}

$\mathrm{CE}$ is a series of related techniques that the separation processes are happened in narrow bore capillaries under the force of electric field [86]. It is a powerful analytical tool that is widely used in the analysis of small organic molecules, inorganic ions and biopolymers [87]. In the years past, $\mathrm{CE}$ has become a hit for drug-protein interaction measurements because of low sample requirements and consumption, simplicity, short analysis times, high sample throughput and high separation efficiencies $[5,88]$. There are several modes of electrophoresis to investigate the drug-protein binding, including affinity CE (ACE), vacancy peak (VP), Hummel-Dreyer method (HD), frontal analysis (FA) and zone migration CE (CZE) [89]. Among them, ACE, FA and CZE have the same advantages: (1) only a small number of proteins and drugs are required; (2) all interacting components can be investigated in free buffer solution at physiological conditions; (3) binding constants of multi-components can be simultaneously estimated. Therefore, these methods are suitable for the study of some Chinese herbal medicines which are chemically complex and expensive [90-93].

In recent years, with the development of microdialysis in the field of medicine, $\mathrm{CE}$ combined with microdialysis techniques has been used in pharmacokinetics research $[94,95]$. It combines the characteristics of continuous, dynamic sampling in microdialysis and less sample volume in CE. The method could objectively analyze the drug-protein binding behavior of specific drugs under physiological and/or pathological conditions. Although there are few reports about the research on CE combined with microdialysis techniques in the field of TCMs, there is no doubt that it is the best choice if you want to study the change of multi-components in Chinese herbal medicine and plasma protein binding in disease states.

\section{Sodium dodecyl sulfate polyacrylamide gel electrophoresis (SDS-PAGE)}

SDS-PAGE, which was proposed by Laemmli in 1970, is a charming and powerful tool for protein characterization [96]. The principle of SDS-PAGE is the positive correlation between electrophoretic mobility of protein and the molecular mass [97-99]. SDS, a kind of anionic 
detergent, could denature original proteins, eliminate protein's original surface charge and destroy the structure. And then the SDS-protein complexes are formed. The advantages of SDS-PAGE are simplicity, less analysis time and excellent repeatability. However, because of the large errors and low resolution of SDS-PAGE, the method cannot reflect the binding degree of drug and the application is rare. Kaldas et al. identified the irreversible binding between oxidized quercetin and protein by a radioactively labelled drug and SDS-PAGE. The result showed that quercetin oxidized by hydrogen/peroxidase covalently links to proteins and with particularly high affinity for HSA [100].

\section{Spectroscopic methods}

\section{The main spectroscopic methods of the interaction} between active herbal components and plasma protein

Spectroscopic methods are based on the change of spectroscopic properties of proteins in ligand-protein binding processes. The information of drug-protein binding can be obtained without separation.

Fluorescence spectroscopy Fluorescence spectroscopy is the most widely used and powerful spectroscopic technique for gaining the information about the binding of drug and plasma proteins because of its accuracy, sensitivity, rapidity and usability [101, 102]. Because of the existence of aromatic, such as tryptophan $(\operatorname{Tr} p)$, tyrosine (Tyr) and phenylalanine (Phe), serum proteins are considered as endogenous fluorescent substance. When $295 \mathrm{~nm}$ is selected as the excitation light source, endogenous fluorescence is all from the Trp residue [103]. When small molecule drugs interact with proteins, they are often able to decrease the fluorescence intensity or quench the intrinsic fluorescence of proteins. Synchronous fluorescence spectrum, which can be obtained by simultaneous scanning excitation wave and emission wave, could determine the emission spectra of Tyr and Trp. Threedimensional fluorescence spectroscopy, a kind of new fluorescence analytical technologies developed in the past 20 years, can visually show the microenvironment and conformational changes under different conditions of $\operatorname{Tr} p$ in protein molecules.

$U V$-Vis absorption spectroscopy UV-Vis absorption spectroscopy is another widely used technique to investigate drug-protein binding. Inherent ultraviolet absorption of plasma protein is mainly due to the absorption of light generated by the $\mathrm{n}-\pi^{*}$ transition in indolyl group of Trp, the phenol group of Tyr and the phenyl group of Phe. The changes of the peak intensity and position of two characteristic absorptions could reflect the conformational change of proteins.
Fourier transform infrared spectroscopy Fourier transform infrared spectroscopy (FT-IR) is one of the popular techniques for the structural characterization of proteins. The most important advantage of FT-IR compared with other methods is the extensive applicability of any biological system in a wide variety of environments $[104,105]$. The characteristic absorption peaks of amide groups of proteins are the most valuable ones for the study of protein secondary structure.

Circular dichroism spectroscopy Circular dichroism (CD) spectroscopy is based on the different absorption of the left and the right circularly polarized light by optically active groups of proteins. The CD spectra of serum proteins are generally divided into two wavelength ranges $-178-250 \mathrm{~nm}$ for the far-ultraviolet $C D$ spectrum and $250-320 \mathrm{~nm}$ for the near-ultraviolet CD spectrum. Extrinsic Cotton effect is used to represent the change of the normal CD spectrum in the binding of ligands to HSA. The far-ultraviolet CD spectrum, the most commonly used spectrum in protein study, could reflect the protein secondary structure information. The peak in the near-ultraviolet region is sensitive to reflect the subtle changes in the conformation of the serum protein.

Surface plasmon resonance (SPR) Surface plasmon resonance (SPR), which can monitor the formation and dissociation of the drug-protein complex in real-time and obtain the equilibrium $\left(K_{\mathrm{D}}\right)$ and kinetic $\left(k_{\text {on }}\right.$ and $\left.k_{\text {off }}\right)$ data for the interaction, is one of the most excellent optical biosensor technologies [106-108]. The conventional SPR device requires a biomolecule to be immobilized on a sensor chip. The sensor chip can monitor the change of refractive index that occurs at the surface of the complexes during form or break process in the binding reaction [108-110]. Another partner in solution is placed together with the sensor. Fabini et al. developed a sensor chip whose serum albumins were covalently bound to the carboxymethyl dextran layer of the sensor chips through its primary amine groups by an amine coupling reaction [111]. The result indicated that cucurbitacins were able to modulate the binding of biliverdin and serum albumins.

Compared with the traditional analytical methods or means, SPR has much salient features such as free label detection, real-time dynamic analysis, non-destructive testing, high sensitivity and larger detection range [112, 113]. Shi et al. developed a rapid, continuous and effective method to identify the multi components from Radix Astragali which were bound to HSA by a SPRHPLC-MS/MS system [114]. The data of reverse ultrafiltration assay showed a good agreement with SPR. SPR has become a popular technique to study DNA-DNA, antibody-antigen, protein-protein interaction and the 
interaction between drugs and specific cellular receptor proteins, key genes, proteases and other disease-related biomolecules.

Besides, there are several commonly used spectra like mass spectrometry (MS), nuclear magnetic resonance (NMR) spectrum, resonance light scattering (RLS) and surface-enhanced Raman scattering spectroscopy. Several spectra are generally used together to study the drugprotein binding and could give more comprehensive data and results.

\section{The main research contents of spectroscopic methods of the interaction between active herbal components and plasma protein}

What we can learn from the result of the spectroscopic methods about the binding between plasma proteins and active herbal components include judging the mechanisms of fluorescence quenching, calculating the binding constant, the number of binding sites, the distance between $\operatorname{Tr} p$ and drug molecule and thermodynamic parameter, determining the binding site, binding forces and change of protein's secondary structure, etc.

Mechanisms of fluorescence quenching The effect of active herbal components on the intrinsic fluorescence of serum albumin can be divided into fluorescence quenching and fluorescence sensitizing. In most cases, fluorescence quenching is the main one. The mechanism of fluorescence quenching can be classified as dynamic quenching and static quenching. The reason for the static quenching is the formation of non-fluorescent complex between the fluorescent molecules in the ground state and quencher [101]. So that the fluorescence spectra of the static quenched fluorescent molecules change. The dynamic quenching is caused by the collision of the fluorescent molecules in the excited state with the quencher. After collision, the fluorescent molecules return to the ground state, so that the fluorescence spectra of the dynamic quenched fluorescent molecules do not change.

The mechanism of fluorescence quenching can be determined by the following points [115].

Firstly, in the Stern-Volmer equation, the value of $K_{q}$ is about $10^{9}-10^{10} \mathrm{~L}(\mathrm{~mol} \mathrm{~s})^{-1}$. If $K_{q}$ calculated from $K_{s v}$ and $\tau_{0}$ is much larger than this range, it means that the binding is not diffusion control and the mechanism of fluorescence quenching is static quenching. Conversely, the mechanism may be dynamic quenching. The $K_{q}$ of delphinidin-3-O-glucoside at $298 \mathrm{~K}$ was $6.163 \times 10^{12} \mathrm{~L} \mathrm{~mol}^{-1} \mathrm{~s}^{-1}$, which was much higher than the maximum diffusion collision quenching constant value $\left(2.0 \times 10^{10} \mathrm{~L} \mathrm{~mol}^{-1} \mathrm{~s}^{-1}\right)$. It illustrated that the interaction of delphinidin-3-O-glucoside with BSA occurred by the static quenching [116].
Secondly, when the dynamic quenching occurs, the UV-Vis absorption spectra of fluorescent molecules do not change. In the event of static quenching, the changes occur on the UV-Vis absorption spectra of fluorescent molecules. HSA had an absorption peak approximately at $280 \mathrm{~nm}$ on the UV-Vis absorption spectra. The increasing neohesperidin dihydrochalcone concentration decreased the absorption peak of HSA and a slight blue shift could be observed. These evidences showed that the interaction between neohesperidin dihydrochalcone and HSA belonged to static quenching [117].

Thirdly, dynamic quenching relies on molecular diffusion. The temperature rise increases the diffusivity of the molecules and the possibility of molecular collision. So the quenching constant increased with temperature. On the contrary, the increase of temperature may reduce the stability of non-fluorescent complex, thereby reducing the degree of static quenching. The value of $K_{s v}$ of ferulic acid was $3.818 \times 10^{4}, 3.912 \times 10^{4}$, and $4.881 \times 10^{4}$ at 25,35 and $45^{\circ} \mathrm{C}$. The trend that the quenching constant increased with the increase of temperature indicated that the interaction of ferulic acid with HSA was influenced by diffusion [118].

And, fourthly, in the case of static quenching, quenching does not change the lifetime of the excited state of fluorescent molecules: $\tau_{0} / \tau=1$. Whereas in the case of dynamic quenching, the presence of the quencher reduces the lifetime of fluorescence: $\mathrm{\tau}_{0} / \tau=F_{0} / F$. Yang et al. found that the increasing concentration of paclitaxel hardly changed the lifetime of HSA (from 5.58 to $5.47 \mathrm{~ns}$ ) and the quenching followed a static mechanism [119].

But for some active herbal components, the static and dynamic procedure may exist simultaneously. Cheng et al. investigated the interaction of tetrandrine with BSA and HSA. The trend that the values of $K_{s v}$ increased with the increasing temperature indicated that the interaction belonged to dynamic quenching [120]. But the UVVis spectra data and the higher $K_{q} \sim 10^{13} \mathrm{~L} \mathrm{~mol}^{-1} \mathrm{~s}^{-1}$ at $298 \mathrm{~K}$ showed the formation of complex. Therefore, a combination of the static and dynamic quenching played an important role in the interaction of tetrandrine with BSA and HSA. Similarly, Gao et al. found an increase of absorbance band intensity on the UV-Vis spectra when the concentration of syringin was increased in HSA [121]. However, the value of $K$ increased with the increasing temperature. Therefore, they thought that the quenching mechanism of HSA by syringin was dynamic quenching, while static quenching could not be ignored.

Binding constant and the number of binding sites Binding constant and the number of binding sites can be calculated by Stern-Volmer equation, modified Stern-Volmer equation, Lineweaver-Burk equation, Benesi-Hidebrand 
equation, Benesi-Hidebrand equation and multiple binding sites equation. Stern-Volmer equation is the most well-known formula which is used to calculate binding constant and the number of binding sites and could apply to study the fluorescence quenching mechanism. Both static quenching and dynamic quenching process follow this equation [19]. Modified Stern-Volmer equation could reduce the effect of other light in the fluorescence experiment on the measured value $[122,123]$. When the linearity of the Stern-Volmer equation is not ideal, the Lineweaver-Burk equation can be used. But Matei et al. predicted slightly higher $K$ values by this model than classical Scatchard equation in the investigation of the kaempferol-HSA complex [124]. They thought that in fact here $K$ represented quenching constant which was used to describe the binding efficiency of the quencher to the fluorescent molecules, but not the binding constant. This equation applies to the system with only one binding site. If the small molecule ligand has fluorescence, its fluorescence intensity increases as it interacts with the protein. Bhattacharya et al. modified the Benesi-Hidebrand equation to escape this interference [125]. This equation is suitable for the active herbal components which have auto-fluorescence [126]. For the multiple binding sites system, Zhang et al. proposed a multiple binding sites equation that could calculate the binding constant and the number of binding sites at the same time [127]. The binding constants and the number of binding sites of N-transp-coumaroyltyramine, 3-trans-feruloyl maslinic acid, four flavonoid aglycones (baicalein, quercetin, daidzein, and genistein) and their monoglycosides (baicalein, quercitrin, daidzin, and puerarin, genistin) were all calculated by this equation [128-130]. It is noteworthy that all the active herbal components using this equation must follow static quenching.

Thermodynamic parameter and bindingforces The binding forces between small molecules and proteins include hydrophobic interactions, electrostatic interactions, hydrogen bonds and van der Waals forces [131]. According to the thermodynamic parameters, the type of binding forces can be roughly determined. The change in enthalpy $(\Delta H)$ can be considered as a constant when the temperature changes a little. Then the values of enthalpy changes and entropy changes $(\Delta S)$ can be calculated from van't Hoff equation. Ross et al. thought that the type of binding forces can be determined by the sign and magnitude of the thermodynamic parameter [132]. The relationship between thermodynamic parameters and binding forces are shown in Table 1.

However, the structure of HSA is very complex and usually there are multiple forces between small molecules and proteins in the actual reaction system. For example,

$\begin{aligned} & \text { Table } 1 \text { The relationship between thermodynamic param- } \\
& \text { eters and binding forces }\end{aligned}$
\begin{tabular}{ll}
\hline Thermodynamic parameter & Binding force \\
\hline$\Delta S>0$ & $\begin{array}{r}\text { May be hydrophobic and electrostatic } \\
\text { interactions } \\
\text { May be hydrogen bonds and van der } \\
\text { Waals forces } \\
\Delta S<0\end{array}$ \\
$\begin{array}{l}\text { Hydrophobic interactions } \\
\text { Hydrogen bonds and van der Waals } \\
\Delta H<0, \Delta S>0\end{array}$ & forces \\
$\Delta H \approx 0$ or very small, $\Delta S>0$ & Electrostatic interactions
\end{tabular}

corresponding thermodynamic parameters about the interaction between HSA and icariin were calculated according to van't Hoff equation [133]. The negative $\Delta H$ and $\Delta S$ were the evidence of van der Waal's force and hydrogen bonds in low dielectric medium. The negative $\Delta H$ was associated with electrostatic interactions. Therefore, electrostatic interactions cannot be excluded from the binding forces.

The distance between Trp in protein and drug molecule Fluorescence resonance energy transfer (FRET) is the distance-dependent interaction that occurs between molecules with different electronic excited states. According to the Förster's non-radiative energy transfer theory, two molecules must meet the following conditions: (1) the energy donor can produce fluorescence; (2) UV-Vis absorption spectra of the energy acceptor and fluorescence emission spectra of the energy donor increasingly overlap; (3) the distance between donor and acceptor is less than $7 \mathrm{~nm}$ [134]. Because the endogenous fluorescence of protein is mainly produced by $\operatorname{Tr} p$ residue, the distance between the binding site of the drug and the Trp residue can be calculated by the Förster's non-radiative energy transfer theory. This theory is widely used in the study of active herbal components-HSA interactions [135-137].

The change of protein's secondary structure The binding process of small molecules and proteins may affect the conformation of proteins. The main techniques to determine the effect of small molecules on the secondary structure of proteins contain UV-Vis absorption spectroscopy, synchronous fluorescence spectroscopy, CD spectroscopy and Fourier transform infrared spectroscopy.

\section{UV-Vis absorption spectroscopy}

When the structure or environment of protein changes, the environment and conformation of the chromophore will also change. And these changes can be expressed 
through the absorption spectra. By comparing the changes of UV-Vis absorption spectra before and after the binding of the active herbal components and HSA, it is possible to determine the presence of the chromophore in the vicinity of the binding site and the change of microenvironment around protein. For example, apigenin has a strong absorption peak at $202 \mathrm{~nm}$ on the UV-Vis spectra [138]. With the increasing of HSA, the position of peaks shifted from 202 to $224 \mathrm{~nm}$ and the absorption intensity decreased. It suggested that quercetin interacted with HSA in ionic form in non-planar conformation, and the binding changed the microenvironment around quercetin.

\section{Synchronous fluorescence spectroscopy}

Synchronous fluorescence spectra can simultaneously scan the excitation and emission wavelengths. The spectral characteristics of a certain amino acid residue can be shown by selecting the appropriate wavelength interval $(\Delta \lambda)$. The synchronous fluorescence spectra of $\Delta \lambda=15 \mathrm{~nm}$ and $\Delta \lambda=60 \mathrm{~nm}$ represent the characteristics of Tyr residues or Trp residues of HSA. The maximum absorption wavelengths of residues are related to the polarity of their environment. Therefore, the change of the conformation of the protein can be judged by the absorption wavelength [138]. Cheng et al. found that significant red shift of the maxima emission wavelength of Trp and Tyr residues when adding tetrandrine to HSA and BSA solution [120]. It indicated that the polarity around the Trp and Tyr residues increased and the hydrophobicity decreased. However, the microenvironment changes of Trp and Tyr residues are not necessarily synchronized. Hedge et al. investigated the molecular environment in the vicinity of a chromophore in the presence of hesperitin [123]. A marginal red shift (from 288 to $290 \mathrm{~nm}$ ) could be observed at $\Delta \lambda=60 \mathrm{~nm}$, while the emission maximum did not exhibit a significant shift at $\Delta \lambda=15 \mathrm{~nm}$. It indicated that the microenvironment around Tyr residue was not affected. But the polarity around the Trp residues increased and the hydrophobicity decreased.

\section{Fourier transform infrared spectroscopy}

The amide bands of protein secondary structure showed a characteristic absorption peak on FT-IR. Among the amide bands of the protein, amide $\mathrm{I}$ band is ranged from 1600 to $1700 \mathrm{~cm}^{-1}$ (mainly $\mathrm{C}=\mathrm{O}$ stretch) and amide II band is at $1550 \mathrm{~cm}^{-1}(\mathrm{C}-\mathrm{N}$ stretch coupled with $\mathrm{N}-\mathrm{H}$ bending mode) [139]. The amide I band is more sensitive to the change of protein secondary structure and more commonly used to test the change of the HSA secondary structure [140]. The assignments of spectral peaks are attributed as follows: $1610-1640 \mathrm{~cm}^{-1}$ to $\beta$-sheet,
$1640-1650 \mathrm{~cm}^{-1}$ to random coil, $1650-1658 \mathrm{~cm}^{-1}$ to $\alpha$-helix, and $1660-1695 \mathrm{~cm}^{-1}$ to $\beta$-turn structure [109]. The absorption peaks of the infrared spectrum often overlap each other to form a broad peak. And the broad infrared bands in the spectra of protein can be analyzed in detail by using second-derivative and deconvolution procedures. The percentage of each secondary structure of protein can be calculated based on the integrated areas of the component bands in amide I [141]. Tang et al. investigated the binding of glycyrrhetinic acid and HSA by multispectroscopic techniques [142]. The FT-IR spectra showed that the peak positions of amide I bands shifted from 1656.40 to $1637.83 \mathrm{~cm}^{-1}$ in HSA infrared spectrum after interaction with glycyrrhetinic acid. It demonstrated that the secondary structures of the HSA had been changed after the binding of glycyrrhetinic acid and HSA. The $\alpha$-helix structure reduced from 50.93 to $24.73 \%, \beta$-turn increased from 23.61 to $25.27 \%$ and random coil appeared (13.98\%).

\section{CD spectroscopy}

The CD spectra of protein have two negative bands at 208 and $222 \mathrm{~nm}$, which is the characteristic feature of $\alpha$-helix structure. The results of CD spectra could be expressed as MRE (mean residue ellipticity) in $\operatorname{deg} \mathrm{cm}^{2} \mathrm{dmol}^{-1}$ and the percentage of $\alpha$-helix can be calculated by equation [143]. By measuring the percentage of $\alpha$-helix, the conformational change of protein could be determined clearly. Liu et al. investigated the impacts of baicalin and rutin on the interaction between curcumin and HSA [144]. The CD spectra showed that curcumin induced a slight decrease in the $\alpha$-helical content of HSA in the absence and presence of rutin and baicalin, corresponding to a reduction of $3.27,8.94$ and $4.81 \%$, respectively. It demonstrated that the effects of curcumin on HSA were slightly less than those of rutin and baicalin.

Binding site Some fluorescent probes have specific binding to different regions of the HSA, and the binding sites can be determined by the displacement binding experiments using some probes. Commonly used florescent probes include: warfarin, phenylbutazone for site 1; ibuprofen, naproxen for site 2 and digitoxin for site 3. Miklós Poór et al. compared the affinity to HSA between flavonoids and warfarin [145]. They found that different flavone (acacetin, chrysin, apigenin, luteolin), flavonol (galangin, quercetin), and flavanone (naringenin, hesperetin) could displace warfarin and highlighted that flavonoids were powerful competitors for HSA and could bind to the drug site 1 . In the competition experiments with ibuprofen probes and warfarin probes for HSA binding sites, Bari et al. demonstrated that quercetin primarily binds to the site located in the subdomain IIA [146]. 
Displacement binding experiments also can be a guidance to reasonably predict clinical toxic and side effect of active herbal components. Soligard et al. used purified Chinese herbal constituents and sulfisoxazole to displace the bilirubin from HSA from jaundiced newborns [147]. The positive inhibitor control sulfisoxazole increased plasma unbound fraction by an average of $60 \%$, while, no displacement phenomena that neferine, sinomenine, tetrahydropalmitine and notoginsenoside showed up. This experiment revealed that four purified Chinese herbal components possessed no significant potential to increase the sulfiisoxazole concentration in jaundiced newborn infants.

\section{Electrochemical methods}

Electrochemical method, which has characteristic of quick response, easy operation and relatively high sensitivity, provides an important tool for the study of protein bioelectrochemistry [148, 149]. As a commonly used electrochemical method, cyclic voltammetry $(\mathrm{CV})$ detects the current signals of the electrochemical substance which is consumed and/or generated during the biological and chemical interaction of the bioactive material and the substrate [150-153]. The method can use mercury, gold, platinum, glassy carbon, carbon fiber microelectrodes, chemically modified electrodes and so on. Based on the analysis of the changes of position, current and number of redox peak, the stoichiometry of the interaction process and the stability constant of supramolecular compounds can be measured, and the binding mode of small drug molecules and proteins can be assumed.

Electrochemical methods can be used to study the molecules whose absorption spectra are weak, or overlaps occur between their electron transition band and the absorption spectrum of the macromolecules themselves. Cyclic voltammetry provides a possibility for the measurement of these molecules, but it is limited to a certain degree by electrical activity [154]. Ni et al. investigated the interaction of quercetin with BSA by UV-Vis absorption spectrometry, fluorescent spectrometry and cyclic voltammetry [155]. The oxidation peak moved from 465 to $520 \mathrm{mV}$ and the reduction peak moved from 430 to $400 \mathrm{mV}$. Corresponding data calculated by equation showed that a 1:1 quercetin-BSA fluorescent complex was formed, but this complex did not appear to be electroactive. That could be due to the electroactive parts of quercetin, the $3^{\prime}$ - and 4'-OH group, were embedded within the BSA, and this prevented its interaction at the electrode surface and therefore its participation in the redox reaction.

\section{Calorimetry}

Calorimetry is the primary source of thermodynamic information which is produced from the heat exchange of any physical, chemical and biological processes. Therefore, calorimetry has become one of the effective tools for studying in many fields of technology and science [156]. Calorimetry could get the basic physical forces that characterize the binding of drug molecule and protein in detail by measuring heat quantities or heat effects. This method can be used as the verification of the results of spectroscopy, which more accurately reflect the binding of active herbal components and plasma proteins. The application of microcalorimetry, including isothermal titration calorimetry (ITC) and differential scanning calorimetry (DSC), makes the calorimetry develop in the direction of high sensitivity and high accuracy.

ITC is the straightest path to complete the thermodynamic characterization of protein interaction without the requirement for chemical modification or labeling [157]. This advantage sets the technique apart from fluorescence spectroscopy, because fluorescence methods often need a quencher to label proteins. Typically, a syringe containing the ligand is titrated into the cells containing the protein solution. With the formation of ligand-protein complex, binding affinity can be evaluated by monitoring the heat that quantitatively occurs in the release and absorption of the binding process $[158,159]$. These experimental data can be fitted into an equation, and the binding constants $\left(K_{\mathrm{b}}\right)$, reaction stoichiometry $(n)$ and thermodynamic parameters, including molar calorimetric enthalpy $\left(\Delta H_{\text {obs }}\right)$, heat capacity $\left(\Delta C_{\mathrm{p}, \mathrm{obs}}\right)$, entropy $\left(\Delta S_{\text {obs }}\right)$ of binding and change in free energy $(\Delta G)$, can be determined accurately $[156,157]$. Zhao et al. developed an ITC combined with CD and UV-Vis spectra method to investigate the interaction of colchicine with HSA [160]. The standard enthalpy of the first class binding site was $29.35 \pm 0.36 \mathrm{~kJ} \mathrm{~mol}^{-1}$ (endothermic process). It indicated that the binding of drug molecules and ligand molecules destroyed the hydration layers. $\Delta H_{0}$ of the second binding site of HSA was $-19.62 \pm 0.28 \mathrm{~kJ} \mathrm{~mol}^{-1}$. It showed the main driving force of the binding was hydrophobic interaction. The thermodynamic parameters showed that the first-class of binding process was primarily driven by entropy and the second-class of binding was driven by enthalpy and entropy. Li et al. presented a new and efficient method of using ITC combined with fluorescence spectroscopy, UV-Vis absorption spectroscopy and Fourier transform infrared (FT-IR) spectroscopy, to study the interaction between $(+)$-catechin and bovine serum albumin (BSA) [161]. Corresponding thermodynamic parameters suggested the binding was synergistically driven by enthalpy and entropy. 
But ITC cannot study very high and low affinity process and the experiments that need a great deal of accurate measurements. Differential scanning calorimetry (DSC) is a complementary technique which could be used to investigate the interaction that is not amenable to analysis by ITC. DSC is developed to investigate thermally induced transitions, especially the conformational transitions of proteins [163]. It can measure the heat difference between a sample and a reference substance at the programmed temperature [163]. The changes of protein structure can be estimated from the relevant thermodynamic parameters, such as phase transition temperature, enthalpy and half-width of the lipoprotein, which could get from DSC curve [164]. Khan et al. investigated the effect of berberine and palmatine on the thermal stability of BSA and HSA by DSC [165]. The melting temperature of BSA and HSA by berberine and palmatine were decreased by (6.00 and 6.02) and (5.70 and 6.01) $\mathrm{K}$, respectively, under saturating conditions. It indicated that the binding destabilized the protein structure. Similarly, the effects of sanguinarine iminium and alkanolamine on the thermal stability of HSA were investigated by DSC, too [166].

\section{Research achievements on the interaction between active herbal components and plasma proteins}

In recent years, the study of the interaction between active herbal components and plasma proteins has been a hot spot. The researchers have carried out a lot of investigations and already gained some achievements in this field. According to the type of compounds, the active herbal components are divided into flavonoids, alkaloids, triterpenes, phenylpropanolds and other phenolic substances. Corresponding binding parameters between different types of active herbal components and plasma proteins are shown in Table 2.

\section{Binding rules between different types of active herbal components and plasma proteins}

Based on the data in Table 2, the properties of different types of active herbal components are significantly different. For the flavonoids, hydrophobic interaction and hydrogen bonds are the major noncovalent interactions between drugs and proteins. Most flavonoid compounds often contain one or more hydroxyl groups, such as $\mathrm{C}-5$ and $\mathrm{C}-7$ in $\mathrm{A}$ ring and $\mathrm{C}-3^{\prime}, \mathrm{C}-4^{\prime}$ and $\mathrm{C}-5^{\prime}$ in $\mathrm{B}$ ring. These hydroxyl groups could form hydrogen bonds with amino acid residue in $\alpha$-helical domains of serum albumin. The major presence of hydrogen bonds in phenylpropanolds may be due to the same reason. Because of the complex structure of alkaloids, the binding forces of them include all the four types. The quenching mechanism of most active herbal components is static. It indicated that complexes can be formed between the active herbal components and plasma proteins, which are conducive to the distribution and pharmacological actions of the active herbal components. The binding site of most active herbal components was site 1 in subdomain IIA of HSA. So the displacement binding of the active herbal components should be taken into consideration in the compatibility of TCMs, so as not to affect the efficacy.

\section{Influence factors on the interaction between active herbal components and plasma proteins}

In practice, because of the complexity and diversity of active components in herbal medicine, an analysis of condition changes of drug binding may promote the understanding of the molecular mechanisms involved and clinical relevance about them. Several factors have significant impacts on the interaction of active herbal components with plasma proteins.

At first, the degree of drug binding to plasma proteins is greatly influenced by $\mathrm{pH}[33,177]$. Many researches have demonstrated the obvious correlation between the binding degree and $\mathrm{pH}$ levels by in vitro assays. By fluorescence quenching method, Cahyana et al. investigated the effects of structure and $\mathrm{pH}$ to the constants for binding of anthocyanins and HSA [178]. The range of the binding constants of anthocyanins with HSA was $1.08 \times 10^{5} \mathrm{M}^{-1}$ to $13.2 \times 10^{5} \mathrm{M}^{-1}$. Due to the special structure of anthocyanin, such as chalcone, hemiacetal, flavyliumcation, quinoidal bases, the binding affinity was $\mathrm{pH}$-dependent. But this dependency was not always positive correlated. Glycosylation and hydroxyl substituents of anthocyanin had lower affinity to HSA at $\mathrm{pH} 4$, but had relatively potent binding at $\mathrm{pH}$ 7.4. However, methylation of a hydroxyl group had the opposite conclusion. The phenomenon that many active herbal components are sensitive to $\mathrm{pH}$ may be due to the existence of the acidic phenolic hydroxyl groups. The polar and charged amino acid residues on the protein surface could react with the phenolic hydroxyl by a hydrogen interaction. The change of $\mathrm{pH}$ could cause different concentrations of the ionization state and then impact the ability of molecules to bind to HSA.

Then, temperature is another main factor in the interaction of active herbal components with plasma protein. The increasing temperature could affect the binding of small molecules and protein for different quenching types. For static quenching, the binding constants decrease with increasing temperature. On the contrary, the binding constants of dynamic quenching process increase with increasing temperature. Cheng et al. demonstrated that the mechanism of the fluorescence quenching of HSA induced by icariin was 


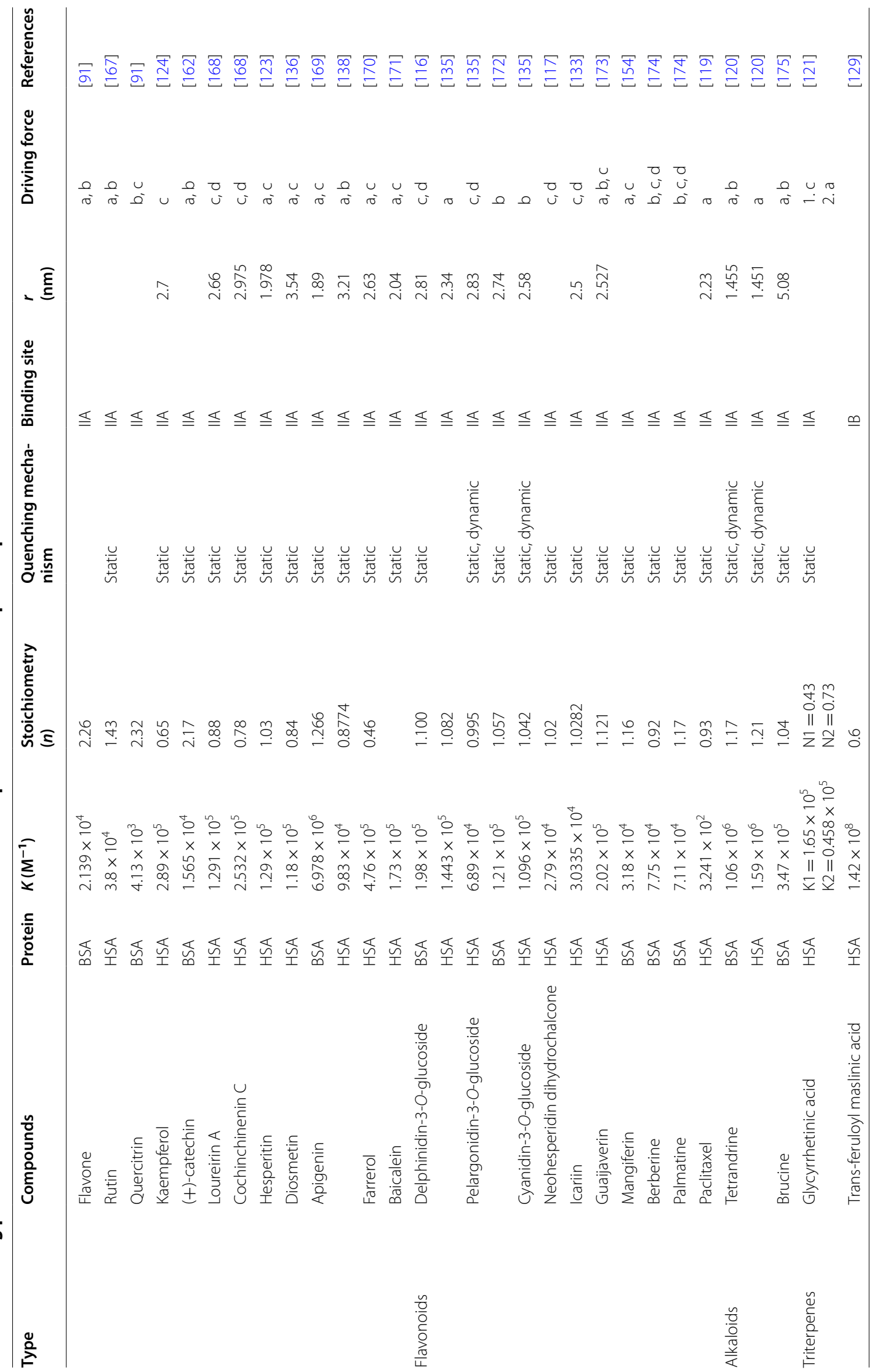




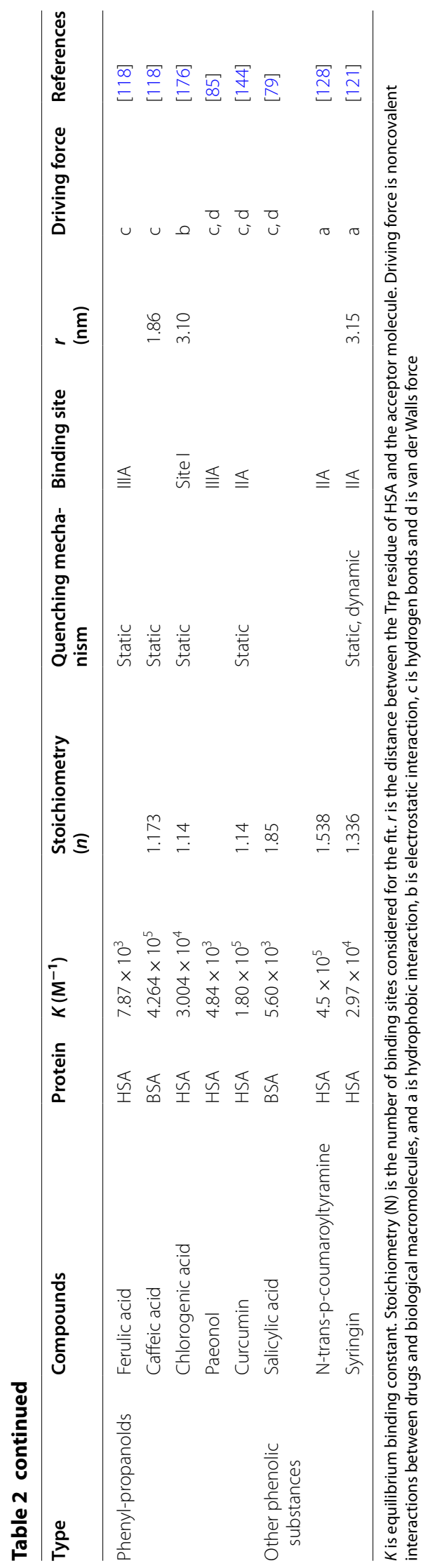


static quenching [133]. The binding constants were $3.0335 \times 10^{4}, 2.0165 \times 10^{4}$ and $1.4227 \times 10^{4} \mathrm{~L} \mathrm{~mol}^{-1}$ at 298,304 and $310 \mathrm{~K}$, respectively, in the fluorescence quenching experiments. The trend that the binding constants vary with increasing temperatures is also the judgement standard of the quenching mechanism.

Afterwards, as trace elements in the blood of the human body, metal ions can act on the active center of the enzyme and play an important role in the normal physiological metabolism. The presence of metal ion directly affects the interaction of plasma proteins with active herbal components. Hu et al. investigated the effects of metal ions on chlorogenic acid-HSA system. Since adding the metal ions $\left(\mathrm{La}^{3+}, \mathrm{Ce}^{3+}, \mathrm{Fe}^{3+}, \mathrm{Cr}^{3+}, \mathrm{Co}^{2+}, \mathrm{Hg}^{2+}\right.$, $\mathrm{Cu}^{2+}, \mathrm{Mn}^{2+}, \mathrm{Zn}^{2+}$ ), the chlorogenic acid-HSA binding constants ranged from 62 to $108 \%$ of the value of the CGA-HSA binding constant without ions [176]. Hegde et al. found that the presence of different concentrations of $\mathrm{Zn}^{2+}$ decreased the binding constants of hesperitinHSA [123]. That might be due to the flexible coordination geometry of the metal ion, which allowed the rapid shift conformations of proteins to perform biological reaction.

Also, the binding is associated with the enantioselective interaction between plasma protein and chiral compounds. Two enantiomers of the same chiral compound have different optical properties, physical and chemical properties and biological activities. Stereoselective difference in PPB between clausenamide (CLA) enantiomers has been found by equilibrium dialysis in rat plasma protein binding [179]. The results of this trial indicated that mean percentages of $(-)$ and $(+)$ CLA in the binding form were 28.5 and $38.0 \%$, respectively. The results explained the stereoselective differences in pharmacokinetics in rats by intravenous drip and oral administration trials between CLA enantiomers. Sun et al. investigated the binding of tetrahydropalmatine (THP) enantiomers and HSA, AGP and proteins in human plasma and found that (+)-THP had higher affinity to HSA and AGP than (-)-THP, respectively [180].

Finally, species differences are also a vital factor that can affect the binding of active components binding and plasma proteins. Liu et al. investigated the plasma protein binding rates of naringin and aglycone naringenin in rat, dog and human plasma by equilibrium dialysis combined with LC-ESI-MS/MS. The plasma protein binding ratios of naringin were found to be $83.30-84.56 \%$, 48.17-51.33\% and $72.14-74.06 \%$ in rat, dog and human plasma, respectively. Gu et al. used equilibrium dialysis followed by LC-MS analysis to assess 20(R)-ginsenoside $\mathrm{Rh}_{2}$ plasma protein binding at four concentration levels (50, 100, 200 and $\left.400 \mathrm{ng} \mathrm{mL}^{-1}\right)$ in rat and human plasma [181]. They suggested that the binding degrees were about $27 \%$ for human plasma and $70 \%$ for rat plasma.
This diversity indicated that species difference was an inevitable factor in new drug development containing 20(R)-ginsenoside $\mathrm{Rh}_{2}$. There are differences between different species about plasma protein binding, but they often have a good correlation [182]. Therefore, measuring the drug binding in other species contributes immeasurably to the forecast of human plasma.

\section{Method selection for different types of active herbal components}

The active herbal components in TCMs are complex and the properties of different types of medicines are quite different. Therefore, the selection of appropriate methods for the drug-protein binding studies would be of great significance. Each method has its own advantages and restrictions, and it depends on the situation.

Firstly, researchers should take into consideration the aim and experimental condition. If you just want to get the binding affinity of the active herbal components and plasma proteins, membrane technology, centrifugation, extraction methods and chromatographic methods are the good choice. While in the advanced drug discovery or development stages, chromatographic methods, electrochemical methods and calorimetry are the methods of choice to obtain a complete view of the binding mechanisms [22]. In these methods, equilibrium dialysis and ultrafiltration are the classical detection methods. These methods are cheap, simple to operate and easily available, and thus they are widely used to evaluate the binding of drug and protein in the early phases of drug development.

Another important consideration is the properties of active herbal components. The classical methods (ED, UF, and UC) are suited to investigate most of the watersoluble compounds. If the water solubility of some active herbal components is low, chromatographic methods, electrochemical methods and calorimetry may fail because the compounds need dissolve into phosphate buffered saline at $\mathrm{pH} 7.4$ in these methods. The advantage of HF-LLPME is that the method can be applied to different physicochemical property drugs with different extraction modes, and the sensitivity and reproducibility are comparable. HF-LLPME is suitable for the extraction of samples with high solubility in the organic phase. For the volatile components in Chinese herbal medicine, like volatile oils which give certain herbs their distinctive aroma, conventional techniques could easily lead to the loss of the samples and affect the final results. Headspace-SPME is much suitable for those components.

Then, researchers need to consider the purity and quantity of the active herbal components. For the low purity compounds, CE and HPAC are better choices. Some active herbal components are expensive and scarce. 
CE inherits its advantages including speediness, low consumption of sample and reagent, high separation efficiency, and availability in the same or similar physiological system conditions. And this method is a good choice for those compounds.

Finally, because of the complexity of the chemical constituents of TCMs, it is important to choose the suitable technique to determine the binding of multi-components in TCMs and plasma proteins simultaneously. HPAC has obvious advantages in investigation of multi-components in TCMs which could react with plasma proteins. Conventional screening methods are blind and massive. HSA or AAG is prepared as the stationary phase of HPAC and affinity chromatography screening model can be established. These components in herbal extracts, which can specifically bind to the receptor protein, are retained in the column, so that the active components in TCMs can be found quickly and effectively. Microdialysis technology can directly obtain the free drug molecules without protein and analyze the concentration of the free drug without pretreatment. Therefore, this method has unique advantages to study the synergistic effect of multi-components, and is a good guidance for the screening of active components in vitro in Chinese herbal medicine. The combination of $\mathrm{CE}$ and microdialysis techniques, which inherits the advantages of both methods, could objectively analyze the drug-protein binding behavior of specific drugs under physiological and/or pathological conditions.

\section{Conclusions}

The safety and efficacy of Chinese herbal medicines have been proven through experience passed on from generation to generation in China. Chinese herbal medicines experienced the change from the single herb to the compound medicines under the guidance of TCM theory and had established itself as a relatively independent disciplinary system. The single active component in Chinese herbal medicines has developed into a multitude of new drugs, and artemisinin is a typical example. Therefore, studies on the binding of active components in Chinese herbal medicines and plasma proteins are of great significance to the guidance and evaluation of new drug development. This article reviewed common techniques including membrane technology, centrifugation, extraction methods, chromatographic methods, spectroscopic methods, electrochemical methods and calorimetry. Rules and influence factors of the binding between different types of active herbal components and plasma proteins are summarized in the end. And some suggestions are also given to help to choose the suitable technique.

But holism is a key element of all systems of traditional medicine and compound prescription is the advantage of traditional Chinese medicine. Under compatibility theory of Chinese medicine, the drugs could enhance effect, reduce toxicity, expand treatment coverage and be an effective preparation for the treatment of complex diseases. The complexity of the compositions of the traditional Chinese medicine prescription has become the biggest obstacle to the further development of traditional medicine. And, based on the existing research results, future studies are worthy to be performed to further study the plasma proteins binding rules of the major active components in single herb or Chinese medicine prescription under the guidance of holism and system biology. More new technologies should be used, and the combination of multiple analytical methods is a new trend to study the interaction between active ingredients of traditional Chinese medicine and plasma proteins. And these studies will, hopefully, be guiding factors in futuristic endeavor to scientifically explain the efficacy and the overall mechanism of action of traditional Chinese medicine.

\section{Abbreviations}

TCM: traditional Chinese medicine; PPB: plasma protein binding; ADMET: absorption, distribution, metabolism, excretion and toxicity; HSA: human serum albumin; AAG: $a_{1}$-acid glycoprotein; BSA: bovine serum albumin; ED: equilibrium dialysis; HPLC: high performance liquid chromatography; RED: rapid equilibrium dialysis; PAMPA: parallel artificial membrane permeability assay; GC-MS: gas chromatography-mass spectrometry; LC-IT-TOF-MS: liquid chromatography-ion trap-time of flight mass spectrometry; RRLC-ESI-MSMS: rapid resolution liquid chromatography-electrospray ionization-mass spectrometry; UF: ultrafiltration; CE: capillary electrophoresis; NMR: nuclear magnetic resonance; UC: ultracentrifugation; SPME: solid phase microextration; HF-LLPME: hollow fiber liquid-liquid phase microextraction; LLE: liquid-liquid extraction; HPAC: high performance affinity chromatography; ACE: affinity capillary electrophoresis; VP: vacancy peak; HD: Hummel-Dreyer; FA: frontal analysis; CZE: zone migration capillary electrophoresis; SDS-PAGE: sodium dodecyl sulfate polyacrylamide gel electrophoresis; Trp: tryptophan;

Tyr: tyrosine; Phe: phenylalanine; FT-IR: fourier transform infrared spectroscopy; CD: circular dichrosim; SPR: surface plasmon resonance; RLS: resonance light scattering; FRET: fluorescence resonance energy transfer; CV: cyclic voltammetry; ITC: isothermal titration calorimetry; DSC: differential scanning calorimetry.

Authors' contributions

QJ, RW, YJ and BL have all been involved in drafting this review. All authors read and approved the final manuscript.

\section{Acknowledgements}

The authors gratefully acknowledge the financial support from the National Natural Science Foundation of China (No. 81173520).

\section{Competing interests}

The authors declare that they have no competing interests.

\section{Availability of data and materials}

The dataset supporting the conclusions of this article is included within the article.

\section{Consent for publication}

Not applicable.

Ethics approval and consent to participate

Not applicable. 


\section{Funding}

This work was supported by the National Natural Science Foundation of China (No. 81173520).

\section{Publisher's Note}

Springer Nature remains neutral with regard to jurisdictional claims in published maps and institutional affiliations.

Received: 21 April 2017 Accepted: 24 April 2018

Published online: 04 May 2018

\section{References}

1. Wang ZG, Ren J (2002) Current status and future direction of Chinese herbal medicine. Trends Pharmacol Sci 23:347-348

2. Vuiginer K, Veuthey J, Carrupt P, Schappler J (2012) Characterization of drug-protein interactions by capillary electrophoresis hyphenated to mass spectrometry. Electrophoresis 33:3306-3315

3. Musteata FM, Pawliszyn J, Qian MG, Wu JT, Miwa GT (2006) Determination of drug plasma protein binding by solid phase microextraction. $J$ Pharm Sci 95:1712-1722

4. Yang XN, Liu JY, Tang X (2008) Pharmacokinetics of salvianolic acids after intravenous injection, with and without Panax quinquefolium protopanaxadiol saponins, in rats. J Ethnopharmacol 3:408-414

5. Gonciarz A, Kus K, Szafarz M, Walczak M, Zakrzewska A, Szymura-Oleksiak J (2012) Capillary electrophoresis/frontal analysis versus equilibrium dialysis in dexamethasone sodium phosphate-serum albumin binding studies. Electrophoresis 33:3323-3330

6. Lohman JJHM, Merkus FWHM, Rahn KH (1986) Plasma protein binding of drugs. Pharm Weekblad 8:302-304

7. Buscher B, Laakso S, Mascher H, Pusecker K, Doig M, Dillen L, WagnerRedeker W, Pfeifer T, Delrat P, Timmerman P (2014) Bioanalysis for plasma protein binding studies in drug discovery and drug development: views and recommendations of the European Bioanalysis Forum. Bioanalysis 6:673-682

8. Howard ML, Hill JJ, Galluppi GR, Mclean MA (2010) Plasma protein binding in drug discovery and development. Comb Chem High Throughput Screen 13:170-187

9. Jia HY, Yang GL, Li ZW, Xin PY, Zhao Y, Chen Y (2007) Micellar liquid chromatography with dodecyl dimethyl betaine as an in vitro method for prediction of protein-drug binding. J Chromatogr A 1143:88-97

10. Wen XD, Qi LW, Chen J, Song Y, Yi L, Yang XW, Li P (2007) Analysis of interaction property of bioactive components in Danggui Buxue Decoction with protein by microdialysis coupled with HPLC-DAD-MS. J Chromatogr B Anal Technol Biomed Life Sci 852:598-604

11. Jiang WY (2005) Therapeutic wisdom in traditional Chinese medicine: a perspective from modern science. Trends Pharmacol Sci 26:558-563

12. Bohnert T, Gan LS (2013) Plasma protein binding: from discovery to development. J Pharm Sci 102:2953-2994

13. Li M, Hagerman AE (2013) Interactions between plasma proteins and naturally occurring polyphenols. Curr Drug Metab 14:432-445

14. Schmidt S, Gonzalez D, Derendorf H (2010) Significance of protein binding in pharmacokinetics and pharmacodynamics. J Pharm Sci 99:1107-1122

15. Li HY, Chen ZX, Xu XJ, Sui XF, Guo T, Liu W, Zhang JW (2011) Predicting human plasma protein binding of drugs using plasma protein interac tion QSAR analysis (PPI-QSAR). Biopharm Drug Dispos 32:333-342

16. Yang $F$, Zhang $Y$, Liang $H$ (2014) Interactive association of drugs binding to human serum albumin. Int J Mol Sci 15:3580-3595

17. Trainor GL (2007) The importance of plasma protein binding in drug discovery. Expert Opin Drug Dis 2:51-64

18. Ascenzi P, Fanali G, Fasano M, Pallottini V, Trezza V (2014) Clinical relevance of drug binding to plasma proteins. J Mol Struct 1077:4-13

19. Zhivkova ZD (2015) Studies on drug-human serum albumin binding: the current state of the matter. Curr Pharm Des 21:1817-1830

20. He XM, Carter DC (1992) Atomic structure and chemistry of human serum albumin. Nature 358:209-215
21. Huang BX, Kim HY, Dass C (2004) Probing three-dimensional structure of bovine serum albumin by chemical cross-linking and mass spectrometry. J Amn Soc Mass Spectr 15:1237-1247

22. Vuignier K, Schappler J, Veuthey JL, Carrupt PA, Martel S (2010) Drugprotein binding: a critical review of analytical tools. Anal Bioanal Chem 398:53-66

23. Wan H, Rehngren M (2006) High-throughput screening of protein binding by equilibrium dialysis combined with liquid chromatography and mass spectrometry. J Chromatogr A 1102:125-134

24. Di L, Umland JP, Trapa PE, Maurer TS (2012) Impact of recovery on fraction unbound using equilibrium dialysis. J Pharm Sci 101:1327-1335

25. Liu ZQ, Jiang ZH, Chan K, Zhou H, Wong YF, Bian ZX, Liu L (2005) Pharmacokinetic interaction of paeoniflorin and sinomenine: pharmacokinetic parameters and tissue distribution characteristics in rats and protein binding ability in vitro. J Pharm Sci 99:381-391

26. Liu ZQ, Chan K, Zhou H, Jiang ZH, Wong YF, Xu HX, Liu L (2005) The pharmacokinetics and tissue distribution of sinomenine in rats and its protein binding ability in vitro. Life Sci 77:3197-3209

27. Wang YL, Yuan JF, Shang W, Zhang J, Zhang ZQ (2011) Dialysis sampling on-line coupled with high-performance liquid chromatography for simultaneous investigation of the interactions between multi-components in herbs and the albumin. Analyst 136:823-828

28. Talbi A, Zhao D, Liu Q, Li J, Fan A, Yang W, Han X, Chen X (2014) Pharmacokinetics, tissue distribution, excretion and plasma protein binding studies of wogonin in rats. Molecules 19:5538-5549

29. Kurz $H$, Trunk $H$, Weitz B (1977) Evaluation of methods to determine protein-binding of drugs. Equilibrium dialysis, ultrafiltration, ultracentrifugation, gel filtration. Arzneimittel-Forsch 27:1373-1380

30. Kochansky CJ, Mcmasters DR, Lu P, Koeplinger KA, Kerr HH, Shou M, Korzekwa KR (2008) Impact of pH on plasma protein binding in equilibrium dialysis. Mol Pharm 5:438-448

31. Curran RE, Claxton CR, Hutchison L, Harradine PJ, Martin IJ, Littlewood P (2011) Control and measurement of plasma $\mathrm{pH}$ in equilibrium dialysis: influence on drug plasma protein binding. Drug Metab Dispos 39:551-557

32. Banker MJ, Clark TH, Williams JA (2003) Development and validation of a 96-well equilibrium dialysis apparatus for measuring plasma protein binding. J Pharm Sci 92:967-974

33. Van LS, Morrison D, Sysmans L, Nelis P, Mortishire-Smith R (2011) Development and validation of a higher-throughput equilibrium dialysis assay for plasma protein binding. J Assoc Lab Autom 16:56-67

34. Xu XS, Rose A, Demers R, Eley T, Ryan J, Stouffer B, Cojocaru L, Arnold M (2014) Quantitative determination of free/bound atazanavir via highthroughput equilibrium dialysis and LC-MS/MS, and the application in ex vivo samples. Bioanalysis 23:3169-3182

35. Waters NJ, Jones R, Williams G, Sohal B (2008) Validation of a rapid equilibrium dialysis approach for the measurement of plasma protein binding. J Pharm Sci 97:4586-4595

36. Kim SB, Lee T, Lee HS, Song CK, Cho HJ, Kim DD, Maeng HJ, Yoon IS (2016) Development and validation of a highly sensitive LC-MS/MS method for the determination of acacetin in human plasma and its application to a protein binding study. Arch Pharm Res 39:213-220

37. Fortuna A, Alves G, Soaresdasilva P, Falcão A (2012) Optimization of a parallel artificial membrane permeability assay for the fast and simultaneous prediction of human intestinal absorption and plasma protein binding of drug candidates: application to dibenz $[b, f]$ azepine-5-carboxamide derivatives. J Pharm Sci 101:530-540

38. Chen X, Murawski A, Patel K, Crespi CL, Balimane PV (2008) A novel design of artificial membrane for improving the PAMPA model. Pharm Res 25:1511-1520

39. Wu YF, Liu H, Ni JM (2011) Advances in parallel artificial membrane permeability assay and its applications. Acta Pharm Sin 46:890-895

40. Singh SP, Wahajuddin Tewari D, Jain GK (2011) PAMPA permeability, plasma protein binding, blood partition, pharmacokinetics and metabolism of formononetin, a methoxylated isoflavone. Food Chem Toxicol 49:1056-1062

41. Banker MJ, Clark TH (2008) Plasma/serum protein binding determinations. Curr Drug Metab 9:854-859

42. Wang C, Williams NS (2013) A mass balance approach for calculation of recovery and binding enables the use of ultrafiltration as a rapid 
method for measurement of plasma protein binding for even highly lipophilic compounds. J Pharm Biomed 75:112-117

43. Tang YH, Zhang SX, Lu Y, Zhu XW (2013) Analysis of plasma protein binding of sophoridine by ultrafiltration and high-performance liquid chromatography. Lat Am J Pharm 32:139-142

44. Tang YH, Zhu HY, Zhang YY, Huang CG (2006) Determination of human plasma protein binding of baicalin by ultrafiltration and high-performance liquid chromatography. Biomed Chromatogr 20:1116-1119

45. Zhao JY, Li L, Jiao FP, Ren FL (2014) Human plasma protein binding of water soluble flavonoids extracted from citrus peelsy. J Cent South Univ 21:2645-2651

46. Shen JM, Liu XY, Tang WJ, Wang J, Zhang HX (2012) Efficient isolation of catechins from green tea and characterization of interaction property of catechins with proteins by HPLC-UV/DAD combined with ultrafiltration. Med Chem Res 21:3549-3556

47. Chen Q, He H, Luo S, Xiong L, Li P (2012) A novel GC-MS method for determination of chrysophanol in rat plasma and tissues: application to the pharmacokinetics, tissue distribution and plasma protein binding studies. J Chromatogr B 973:76-83

48. Zhao G, Peng C, Du W, Wang S (2014) Simultaneous determination of imperatorin and its metabolites in vitro and in vivo by a GC-MS method: application to a bioavailability and protein binding ability study in rat plasma. Biomed Chromatogr BMC 28:947-956

49. Liang Y, Zhou YY, Liu YN (2013) Study on the plasma protein binding rate of Schisandra lignans based on the LC-IT-TOF/MS technique with relative quantitative analysis. Chin J Nat Med 11:442-448

50. Luo Y, Wu S, Li X, Li P (2010) LC-ESI-MS-MS determination of rat plasma protein binding of major flavonoids of Flos Lonicerae Japonicae by centrifugal ultrafiltration. Chromatographia 72:71-77

51. Li JM, Shi QW, Jiang Y, Liu Y (2015) Pretreatment of plasma samples by a novel hollow fiber centrifugal ultrafiltration technique for the determination of plasma protein binding of three coumarins using acetone as protein binding releasing agents. J Chromatogr B 1001:114-123

52. Zetterström T, Vernet L, Ungerstedt U, Tossman U, Jonzon B, Fredholm BB (1982) Purine levels in the intact rat brain. Studies with an implanted perfused hollow fibre. Neurosci Lett 29:111-115

53. Huang $H$, Zhang $Y$, Yang $R$, Tang $X$ (2008) Determination of baicalin in rat cerebrospinal fluid and blood using microdialysis coupled with ultra-performance liquid chromatography-tandem mass spectrometry. J Chromatogr B 874:77-83

54. Wang HL, Zou HF, Feng AS, Zhang YK (1997) Binding of sulfamethoxazole to human serum albumin studied by a combined technique of microdialysis with liquid chromatography. Anal Chim Acta 342:159-165

55. Elmquist WF, Sawchuk RJ (2000) Use of microdialysis in drug delivery studies. Adv Drug Deliv Rev 45:123-124

56. Wang H, Zou H, Zhang Y (1998) Quantitative study of competitive binding of drugs to protein by microdialysis/high-performance liquid chromatography. Anal Chem 70:373-377

57. Yang XN, Wang YJ, Liu YS, Tang X (2008) Pharmacokinetics of salvianolic acids after intravenous injection, with and without Panax quinquefolium protopanaxadiol saponins, in rats. J Ethnopharmacol 117:408-414

58. Qian ZM, Wen XD, Li HJ, Liu Y, Qin SJ, Li P (2008) Analysis of interaction property of bioactive components in Flos Lonicerae Japonicae with protein by microdialysis coupled with HPLC-DAD-MS. Biol Pharm Bull 31:126-130

59. Guo M, Su X, Kong L, Li X, Zou H (2006) Characterization of interaction property of multicomponents in Chinese Herb with protein by microdialysis combined with HPLC. Anal Chim Acta 556:183-188

60. Chuang VT, Maruyama T, Otagiri M (2009) Updates on contemporary protein binding techniques. Drug Metab Pharmacokinet 24:358-364

61. Srikanth CH, Chaira T, Sampathi S, Sreekumar VB, Bambal RB (2013) Correlation of in vitro and in vivo plasma protein binding using ultracentrifugation and UPLC-tandem mass spectrometry. Analyst 138:6106-6116

62. Li QH, Cui MY, Sui XP, Li YJ (2008) Determination of protein bound fraction of serum of syringopicroside. J Harbin Univ Commer (Nat Sci Ed) 24:148-150

63. Hester P, Bosman IJ, Hermens JLM (2015) Sensitive determination of plasma protein binding of cationic drugs using mixed-mode solidphase microextraction. J Pharm Biomed 115:534-542

64. Goryński K, Goryńska P, Górska A, Harężlak T, Jaroch A, Jaroch K, Lendor S, Skobowiat C, Bojko B (2016) SPME as a promising tool in translational medicine and drug discovery: from bench to bedside. J Pharm Biomed 130:55-67

65. Kramer NI, Eijkeren JCHV, Hermens JLM (2007) Influence of albumin on sorption kinetics in solid-phase microextraction: consequences for chemical analyses and uptake processes. Anal Chem 79:6941-6948

66. Theodoridis $G$ (2006) Application of solid-phase microextraction in the investigation of protein binding of pharmaceuticals. J Chromatogr B 830:238-244

67. Musteata FM, Pawliszyn J, Qian MG, Wu JT, Miwa GT (2006) Determination of drug plasma protein binding by solid phase microextraction. J Pharm Sci 95:1712-1722

68. Vaes WHJ, Ramos EU, Verhaar HJM, Seinen W, Hermens JLM (1996) Measurement of the free concentration using solid-phase microextraction: binding to protein. Anal Chem 86:4463-4467

69. Aresta A, Grumo FD, Zambonin C (2016) Determination of major isoflavones in soy drinks by solid-phase micro extraction coupled to liquid chromatography. Food Anal Method 9:1-9

70. Dymerski T, Namieśnik J, Leontowicz H, Leontowicz M, Vearasilp K, Martinez-Ayala AL, González-Aguilar GA, Robles-Sánchez M (2016) Chemistry and biological properties of berry volatiles by two-dimensional chromatography, fluorescence and Fourier transform infrared spectroscopy techniques. Food Res Int 83:74-86

71. Hu L, Chen D (2009) Application of headspace solid phase microextraction for study of noncovalent interaction of borneol with human serum albumin. Acta Pharmacol Sin 30:1573-1576

72. Trtić-Petrović T, Liu JF, Jönsson JÅ (2005) Equilibrium sampling through membrane based on a single hollow fibre for determination of drugprotein binding and free drug concentration in plasma. J Chromatogr B 826:169-176

73. Fu H, Guan J, Bao JJ (2007) A hollow fiber solvent microextraction approach to measure drug-protein binding. Anal Sci 22:1565-1569

74. Hatami M, Farhadi K (2012) Application of hollow fiber-supported liquid-phase microextraction coupled with HPLC for the determination of guaifenesin enantiomer-protein binding. Biomed Chromatogr 26:875-880

75. Hu S, Zhang YJ, Bai XH (2011) Rapid and simultaneous study on drugprotein binding of four furocoumarins by hollow fiber liquid phase microextraction. Biomed Chromatogr 74:503-506

76. Xi GC, Hu S, Bai XH (2011) Simple and rapid hollow fiber liquid phase microextraction followed by high performance liquid chromatography method for determination of drug-protein binding. Chem Res Chin U 27:764-768

77. Hage DS, Jackson A, Sobansky MR, Schiel JE, Yoo MJ, Joseph KS (2009) Characterization of drug-protein interactions in blood using highperformance affinity chromatography. J Sep Sci 32:835-853

78. Vuignier K, Guillarme D, Veuthey JL, Carrupt PA, Schappler J (2013) High performance affinity chromatography (HPAC) as a high-throughput screening tool in drug discovery to study drug-plasma protein interactions. J Pharm Biomed 74:205-212

79. Xuan H, Joseph KS, Wa C, Hage DS (2010) Biointeraction analysis of carbamazepine binding to alpha1-acid glycoprotein by high-performance affinity chromatography. J Sep Sci 33:2294-2301

80. Yoo MJ, Smith QR, Hage DS (2009) Studies of imipramine binding to human serum albumin by high-performance affinity chromatography. $J$ Chromatogr B 887:1149-1154

81. Mallik R, Yoo MJ, Chen S, Hage DS (2008) Studies of verapamil binding to human serum albumin by high-performance affinity chromatography. J Chromatogr B 876:69-70

82. Kim HS, Wainer IW (2008) Rapid analysis of the interactions between drugs and human serum albumin (HSA) using high-performance affinity chromatography (HPAC). J Chromatogr B 870:22-26

83. Li YF, Zhang XQ, Hu WY, Li Z, Liu PX, Zhang ZQ (2013) Rapid screening of drug-protein binding using high-performance affinity chromatography with columns containing immobilized human serum albumin. J Anal Methods Chem. https://doi.org/10.1155/2013/439039

84. Cai X, Zhang Y, Yu L, Guo Z, Zhang X, Liang X (2011) Detection of drug-human serum albumin binding ratios of two Chinese medicinal ingredients by high performance affinity chromatography. Chin J Chromatogr 29:358-367

85. Lei GH, Liu LT, Dai XJ, Wei YM, Gong BL (2010) Investigation on the competition interaction of ferulic acid and paeonol with human serum 
albumin by high-performance affinity chromatography. Acta Chim Sin 68:55-61

86. Anastos N, Barnett NW, Lewis SW (2005) Capillary electrophoresis for forensic drug analysis: a review. Talanta 67:269-279

87. Zhao X, You T, Liu J, Sun XH, Yan JL, Yang XR, Wang EK (2004) Drughuman serum albumin binding studied by capillary electrophoresis with electrochemiluminescence detection. Electrophoresis 25:3422-3426

88. Shibukawa A, Yoshimoto Y, Ohara T, Nakagawa T (1994) High-performance capillary electrophoresis/frontal analysis for the study of protein binding of a basic drug. J Pharm Sci 83:616-619

89. He XY, Ding YS, Li DZ, Lin BC (2004) Recent advances in the study of biomolecular interactions by capillary electrophoresis. Electrophoresis 25:697-711

90. Diniz A, Escuder-Gilabert L, Lopes NP, Villanueva-Camañas RM, Sagrado S, Medina-Hernández MJ (2008) Characterization of interactions between polyphenolic compounds and human serum proteins by capillary electrophoresis. Anal Bioanal Chem 391:625-632

91. Knjazeva T, Kaljurand M (2010) Capillary electrophoresis frontal analysis for the study of flavonoid interactions with human serum albumin. Anal Bioanal Chem 397:2211-2219

92. Zinellu A, Sotgia S, Scanu B, Pisanu E, Giordo R, Cossu A, Posadino AM, Carru C, Pintus G (2014) Evaluation of non-covalent interactions between serum albumin and green tea catechins by affinity capillary electrophoresis. J Chromatogr A 1367:167-171

93. Michalcová L, Glatz Z (2014) Comparison of various capillary electrophoretic approaches for the study of drug-protein interaction with emphasis on minimal consumption of protein sample and possibility of automation. J Sep Sci 38:325-331

94. Arnett SD, Osbourn DM, Moore KD, Vandaveer SS, Lunte CE (2005) Determination of 8-oxoguanine and 8-hydroxy-2'-deoxyguanosine in the rat cerebral cortex using microdialysis sampling and capillary electrophoresis with electrochemical detection. J Chromatogr B 817:16-25

95. Parrot S, Sauvinet V, Riban V, Depaulis A, Renaud B, Denoroy L (2004) High temporal resolution for in vivo monitoring of neurotransmitters in awake epileptic rats using brain microdialysis and capillary electrophoresis with laser-induced fluorescence detection. J Neurosci Methods 140:29-38

96. Ficheux A, Gayrard N, Szwarc I, Andress D, Soullier S, Duny Y, Goubert G, Thomas M, Bismuth-Mondolfo J, Daurès JP, Brunet P, Servel MF, Argilés A (2011) The use of SDS-PAGE scanning of spent dialysate to assess uraemic toxin removal by dialysis. Nephrol Dial Transpl 26:2281-2289

97. Zhang T, Gai Q, Qu F, Zhang Y (2011) lonic liquid-assisted SDSPAGE to improve human serum protein separation. Electrophoresis 20:2904-2910

98. Kanerva P, Sontagstrohm T, Lehtonen P (2005) Determination of prolamins in beers by ELISA and SDS-PAGE. J Inst Brew 111:61-64

99. Jeon YT, Ruzicka MR, Cho IK, Li QX, Kim SU (2011) Heating of freezedried protein samples with urea for SDS-PAGE in proteomics study. Appl Biol Chem 54:19-23

100. Kaldas MI, Walle UK, Van Der Woude H, Mcmillan JM, Walle T (2005) Covalent binding of the flavonoid quercetin to human serum albumin. J Agr Food Chem 53:4194-4197

101. Jian Y, Zheng HJ, Jin JJ, Guo P (2009) Fluorescence spectroscopy study on the interaction between Gossypol and bovine serum albumin. J Mol Struct 920:227-230

102. Seedher N, Bhatia S (2005) Mechanism of interaction of the non-steroidal antiinflammatory drugs meloxicam and nimesulide with serum albumin. J Pharm Biomed 39:257-262

103. Sułkowska A, Równicka J, Bojko B, Sułkowski W (2003) Interaction of anticancer drugs with human and bovine serum albumin. J Mol Struct 651-653:133-140

104. Surewicz WK, Mantsch HH, Chapman D (1999) Determination of protein secondary structure by Fourier transform infrared spectroscopy: a critical assessment. Biochemistry 32:389-394

105. Li Y, He W, Dong Y, Sheng F, Hu Z (2000) Human serum albumin interaction with formononetin studied using fluorescence anisotropy, FT-IR spectroscopy, and molecular modeling methods. Bioorgan Med Chem 14:1431-1436

106. Rowland A, Hallifax D, Nussio MR, Shapter JG, Mackenzie PI, Brian Houston J, Knights KM, Miners JO (2015) Characterization of the comparative drug binding to intra- (liver fatty acid binding protein) and extra- (human serum albumin) cellular proteins. Xenobiotica 45:1-11

107. Karlsson R, Fält A (1997) Experimental design for kinetic analysis of protein-protein interactions with surface plasmon resonance biosensors. J Immunol Methods 200:121-133

108. Bala C (2015) Surface plasmon resonance (SPR) biosensors in pharmaceutical analysis. Crit Rev Anal Chem 45:97-105

109. Patching SG (2014) Surface plasmon resonance spectroscopy for characterisation of membrane protein-ligand interactions and its potential for drug discovery. Biochim Biophys Acta 1838:43-55

110. Liu X, Song DQ, Zhang QL, Tian Y, Liu ZY, Zhang HQ (2006) Characterization of drug-binding levels to serum albumin using a wavelength modulation surface plasmon resonance sensor. Sens Actuators B Chem 117:188-195

111. Fabini E, Fiori GM, Tedesco D, Lopes NP, Bertucci C (2016) Surface plasmon resonance and circular dichroism characterization of cucurbitacins binding to serum albumins for early pharmacokinetic profiling. J Pharm Biomed 122:166-172

112. Vachali PP, Li B, Bartschi A, Bernstein PS (2015) Surface plasmon resonance (SPR)-based biosensor technology for the quantitative characterization of protein-carotenoid interactions. Arch Biochem Biophys 572:66-72

113. Vuignier K, Veuthey JL, Carrupt PA, Schappler J (2013) Global analytical strategy to measure drug-plasma protein interactions: from highthroughput to in-depth analysis. Drug Discov Today 18:1030-1034

114. Zhang Y, Shi S, Guo J, You Q, Feng D (2013) On-line surface plasmon resonance-high performance liquid chromatography-tandem mass spectrometry for analysis of human serum albumin binders from Radix Astragali. J Chromatogr A 1293:92-99

115. Lakowicz JR (1999) Principles of fluorescence spectroscopy, 2nd edn. Kluwer Academic Publishers/Plenum Press, New York

116. Zuo H, Tang L, Li S, Huang J (2015) Combined multispectroscopic and molecular docking investigation on the interaction between delphinidin-3-O-glucoside and bovine serum albumin. Luminescence 30:110-117

117. Bozoğlan BK, Tunç S, Duman O (2014) Investigation of neohesperidin dihydrochalcone binding to human serum albumin by spectroscopic methods. J Lumin 155:198-204

118. Li S, Huang K, Zhong M, Guo J, Wang WZ, Zhu R (2010) Comparative studies on the interaction of caffeic acid, chlorogenic acid and ferulic acid with bovine serum albumin. Spectrochim Acta A 77:680-686

119. Yang $X$, Ye Z, Yuan $Y$, Zheng Z, Shi J, Ying Y, Huang P (2013) Insights into the binding of paclitaxel to human serum albumin: multispectroscopic studies. Luminescence 28:427-434

120. Cheng Z, Liu R, Jiang X (2013) Spectroscopic studies on the interaction between tetrandrine and two serum albumins by chemometrics methods. Spectrochim Acta A 115:92-105

121. Gao W, Li N, Chen Y, XU Y, Lin Y, Yin Y, Hu Z (2010) Study of interaction between syringin and human serum albumin by multi-spectroscopic method and atomic force microscopy. J Mol Struct 83:133-140

122. Maiti TK, Ghosh KS, Dasgupta S (2006) Interaction of (-)-epigallocatechin-3-gallate with human serum albumin: fluorescence, fourier transform infrared, circular dichroism, and docking studies. Proteins 64:355-362

123. Hegde AH, Sandhya B, Seetharamappa J (2011) Evaluation of binding and thermodynamic characteristics of interactions between a citrus flavonoid hesperitin with protein and effects of metal ions on binding. Mol Biol Rep 38:4921-4929

124. Matei I, Hillebrand M (2010) Interaction of kaempferol with human serum albumin: a fluorescence and circular dichroism study. J Pharm Biomed 51:768-773

125. Bhattacharyya J, Bhattacharyya M, Chakrabarty AS, Chaudhuri U, Poddar RK (1994) Interaction of chlorpromazine with myoglobin and hemoglobin. A comparative study. Biochem Pharmacol 47:2049-2053

126. Subramanyam R, Gollapudi A, Bonigala P, Chinnaboina M, Amooru DG (2009) Betulinic acid binding to human serum albumin: a study of protein conformation and binding affinity. J Photochem Photobiol B Biol 94:8-12

127. Zhang Y, Zhang GZ, Wang YM (2000) Studies of interaction of mitomycin $C$ and serum albumin by spectrum method. J Anal Sci 16:445-449 
128. Neelam S, GokaraM Sudhamalla B, Amooru DG, Subramanyam R (2010) Interaction studies of coumaroyltyramine with human serum albumin and its biological importance. J Phys Chem B 114:3005-3012

129. Subramanyam R, Goud M, Sudhamalla B, Reddeem E, Gollapudi A, Nellaepalli S, Yadavalli V, Chinnaboina M, Amooru DG (2009) Novel binding studies of human serum albumin with trans-feruloyl maslinic acid. J Photochem Photobiol B Biol 95:81-88

130. Xiao J, Cao H, Wang Y, Zhao J, Wei X (2009) Glycosylation of Dietary Flavonoids Decreases the Affinities for Plasma Protein. J Agr Food Chem 57:6642-6648

131. Leckband D (2000) Measuring the forces that control protein interactions. Annu Rev Biophys Biomol Struct 29:1-26

132. Ross PD, Subramanian S (1981) Thermodynamics of protein association reactions: forces contributing to stability. Biochemistry 20:3096-3102

133. Cheng X, Fan X, Jiang F, Liu Y, Lei K (2015) Resonance energy transfer, $\mathrm{pH}$-induced folded states and the molecular interaction of human serum albumin and icariin. Luminescence 30:1026-1033

134. Förster T, Sinanoglu O (1966) Modern Quantum Chemistry. Academic Press, New York

135. Tang L, Zuo H, Shu L (2014) Comparison of the interaction between three anthocyanins and human serum albumins by spectroscopy. J Lumin 153:54-63

136. Zhang G, Wang L, Pan J (2012) Probing the binding of the flavonoid diosmetin to human serum albumin by multispectroscopic techniques. J Agr Food Chem 60:2721-2729

137. Sheng F, Wang Y, Zhao X, Tian N, Hu H, Li P (2014) Separation and identification of anthocyanin extracted from mulberry fruit and the pigment binding properties toward human serum albumin. J Agr Food Chem 62:6813-6819

138. Yuan JL, Lv Z, Liu ZG, Hu Z, Zou GL (2007) Study on interaction between apigenin and human serum albumin by spectroscopy and molecular modeling. J Instrum Anal 191:104-113

139. Kanakis CD, Tarantilis PA, Polissiou MG, Diamantoglou S, Tajmir-Riahi HA (2006) Antioxidant flavonoids bind human serum albumin. J Mol Struct 798:69-74

140. Tang JH. Study on interaction of several organic small molecules substances with human serum albumin. PhD thesis. Lanzhou University: College of Chemistry and Chemical Engineering. 2006

141. Haris PI, Severcan F (1999) FTIR spectroscopic characterization of protein structure in aqueous and non-aqueous media. J Mol Catal B Enzym 7:207-221

142. Tang J, Luan F, Chen X (2006) Binding analysis of glycyrrhetinic acid to human serum albumin: fluorescence spectroscopy, FTIR, and molecular modeling. Bioorgan Med Chem 14:3210-3217

143. Greenfield NJ, Fasman GD (1969) Computed circular dichroism spectra for the evaluation of protein conformation. Biochemistry 10:4108-4116

144. Liu BM, Zhang J, Hao AJ, Xu L, Wang D, Ji H, Sun SJ, Chen BQ, Liu B (2015) The increased binding affinity of curcumin with human serum albumin in the presence of rutin and baicalin: a potential for drug delivery system. Spectrochim Acta A 155:88-94

145. Poór M, Li Y, Kunsági-Máté S, Petrik J, Vladimir-Knežević S, Kőszegi T (2013) Molecular displacement of warfarin from human serum albumin by flavonoid aglycones. J Lumin 142:122-127

146. Bari LD, Ripoli S, Pradhan S, Salvadori P (2010) Interactions between quercetin and Warfarin for albumin binding: a new eye on food/drug interference. Chirality 22:593-596

147. Soligard HT, Bratlid D, Cao C, Liang A, Nilsen OG (2011) Displacement of Bilirubin from Albumin in Plasma from Jaundiced Newborns. An in vitro study of purified Chinese herbal constituents and sulfisoxazole. Phytother Res 25:1068-1072

148. Sun B, Gou Y, Xue Z, Zheng X, Ma Y, Hu F, Zhao W (2016) Protections of bovine serum albumin protein from damage on functionalized graphene-based electrodes by flavonoids. Mater Sci Eng C 62:197-205

149. Daneshegar P, Moosavimovahedi AA, Norouzi P, Reza GM, Mohammad F, Nader S (2012) Characterization of paracetamol binding with normal and glycated human serum albumin assayed by a new electrochemical method. J Brazil Chem Soc 23:315-321

150. Tang DP, Yuan $R$, Chai $Y Q$ (2006) Novel immunoassay for carcinoembryonic antigen based on protein A-conjugated immunosensor chip by surface plasmon resonance and cyclic voltammetry. Bioprocess Biosyst Eng 28:315-321
151. Gowda Jl, Nandibewoor ST (2014) Binding and conformational changes of human serum albumin upon interaction with 4-aminoantipyrine studied by spectroscopic methods and cyclic voltammetry. Spectrochim Acta A 124:397-403

152. Um HJ, Kim M, Lee SH, Min J, Kim H, Choi YW, Kim YH (2011) Electrochemically oriented immobilization of antibody on poly-(2-cyanoethylpyrrole)-coated gold electrode using a cyclic voltammetry. Talanta 84:330-334

153. Xiao CQ, Jiang FL, Zhou B, Li R, Liu Y (2011) Interaction between a cationic porphyrin and bovine serum albumin studied by surface plasmon resonance, fluorescence spectroscopy and cyclic voltammetry. Photochem Photobio Sci 10:1110-1117

154. Freitas PG, Barbosa AF, Saraiva LA, Camps I, Silveiraand NJFD, Veloso MP, Santors MH, Schneedorf JM (2012) Mangiferin binding to serum albumin is non-saturable and induces conformational changes at high concentrations. J Lumin 132:3027-3034

155. Ni Y, Zhang $X$, Kokot S (2009) Spectrometric and voltammetric studies of the interaction between quercetin and bovine serum albumin using warfarin as site marker with the aid of chemometrics. Spectrochim Acta A 71:1865-1872

156. Saboury AA (2006) A review on the ligand binding studies by isothermal titration calorimetry. J Iran Chem Soc 3:1-21

157. Callies O, Daranas AH (2016) Application of isothermal titration calorimetry as a tool to study natural product interactions. Nat Prod Rep 33:881-904

158. Liang $Y$ (2008) Applications of isothermal titration calorimetry in protein science. Acta Biochim et Biophys Sin 40:565-576

159. Grolier JPE, Rio JMD (2012) Isothermal titration calorimetry: a thermodynamic interpretation of measurements. J Chem Thermodyn 55:193-202

160. Zhao Q, Xu XY, Sun XJ, Liu M, Sun DZ, Li LW (2009) A calorimetric study on interactions of colchicine with human serum albumin. J Mol Struct 931:31-34

161. Li X, Hao Y (2015) Probing the binding of (+)-catechin to bovine serum albumin by isothermal titration calorimetry and spectroscopic techniques. J Mol Struct 1091:109-117

162. Bruylants G, Wouters J, Michaux C (2005) Differential scanning calorimetry in life science: thermodynamics, stability, molecular recognition and application in drug design. Curr Med Chem 12:2011-2020

163. Celej MS, Dassie SA, González M, Bianconi ML, Fidelio GD (2006) Differential scanning calorimetry as a tool to estimate binding parameters in multiligand binding proteins. Anal Biochem 350:227-284

164. Burgos MI, Fernández RA, Celej MS, Rossi LI, Fidelio GD, Dassie SA (2011) Binding of the highly toxic tetracycline derivative, anhydrotetracycline, to bovine serum albumin. Biol Pharm Bull 34:1301-1306

165. Khan AY, Hossain M, Kumar GS (2013) Binding of plant alkaloids berberine and palmatine to serum albumins: a thermodynamic investigation. Mol Biol Rep 403:553-566

166. Hossain M, Khan AY, Kumar GS (2012) Study on the thermodynamics of the binding of iminium and alkanolamine forms of the anticancer agent sanguinarine to human serum albumin. J Chem Thermodyn 47:90-99

167. Pastukhov AV, Levchenko LA, Sadkov AP (2007) Spectroscopic study on binding of rutin to human serum albumin. J Mol Struct 842:60-66

168. Chen X, Qian K, Chen Q (2015) Comparison between loureirin A and cochinchinenin $C$ on the interaction with human serum albumin. Eur J Med Chem 93:492-500

169. Shang Y, Li H (2010) Studies of the interaction between apigenin and bovine serum albumin by spectroscopic methods. Russ J Gen Chem 80:1710-1717

170. Jin J, Zhu J, Yao X, Wu L (2007) Study on the binding of farrerol to human serum albumin. J Photochem Photobiol A Chem 191:59-65

171. Wang J, Wang Q, Wu D, Yan J, Wu Y, Li H (2015) Comparative studies on the interactions of baicalein and $\mathrm{Al}(\mathrm{III})$-baicalein complex with human serum albumin. Luminescence 31:54-62

172. Li S, Tang L, Bi H (2016) Study on the interaction between pelargonidin-3-O-glucoside and bovine serum albumin using spectroscopic, transmission electron microscopy and molecular modeling techniques. Luminescence 31:442-452

173. Caruso ÍP, Vilegas W, Fossey MA, Cornélio ML (2012) Exploring the binding mechanism of Guaijaverin to human serum albumin: fluorescence 
spectroscopy and computational approach. Spectrochim Acta A 97:449-455

174. Marszalek M, Konarska A, Szajdzinskapietek E, Wolszczak M (2013) Interaction of cationic protoberberine alkaloids with human serum albumin No spectroscopic evidence on binding to Sudlow's site 1. J Phys Chem B 117:15987-15993

175. Zhang HM, Fei ZH, Tang BP, Chen J, Tao WH, Wang YQ (2012) The interaction of blood proteins with brucine. Mol Biol Rep 39:4937-4947

176. Hu YJ, Chen CH, Zhou S, Bai AM, Yu OY (2012) The specific binding of chlorogenic acid to human serum albumin. Mol Biol Rep 39:2781-2787

177. Liu MH, Zou W, Fan LD, Li PB, Su WW (2012) Comparative protein binding of naringin and its aglycone naringenin in rat, dog and human plasma. Afr J Pharm Pharm 6:934-940

178. Cahyana Y, Gordon MH (2013) Interaction of anthocyanins with human serum albumin: influence of $\mathrm{pH}$ and chemical structure on binding. Food Chem 141:2278-2285
179. Zhu CJ, Zhang JT (2009) Stereoselective plasma protein binding and target tissue distribution of clausenamide enantiomers in rats. Chirality 21:402-406

180. Sun DL, Huang SD, Wu PS, Li J, Ye YJ, Jiang HD (2010) Stereoselective protein binding of tetrahydropalmatine enantiomers in human plasma, HSA, and AGP, but not in rat plasma. Chirality 22:618-623

181. Gu Y, Wang G, Sun J, Jia Y, Xu M, Wang W (2006) In vitro assessment of plasma protein binding of 20(R)-ginsenoside Rh2 by equilibrium dialysis and LC-MS analysis: a case of species differences. Biol Pharm Bull 29:951-956

182. Colclough N, Ruston L, Wood JM, Macfaul PA (2006) Species differences in drug plasma protein binding. MedChemComm 5:963-967

\section{Submit your manuscript to a SpringerOpen ${ }^{\circ}$ journal and benefit from:}

- Convenient online submission

- Rigorous peer review

- Open access: articles freely available online

- High visibility within the field

- Retaining the copyright to your article

Submit your next manuscript at $\boldsymbol{\nabla}$ springeropen.com 